8 Abstract

9

Abstract

Keywords:

\title{
Sr immobilization in irradiated Portland cement paste exposed to carbonation
}

\author{
Gabriela Bar-Nes $^{1 *}$, Ofra Klein-BenDavid ${ }^{1}$, Laure Chomat $^{2}$, Nathalie Macé2, Michal Arbel-Haddad ${ }^{1}$, \\ Stephane Poyet ${ }^{2}$ \\ ${ }^{1}$ Department of Applied Chemistry, NRCN, P.O. Box 9001, Beer-Sheva, Israel. \\ ${ }^{2}$ Den-Service d'Etude du Comportement des Radionucléides (SECR), CEA, Université Paris-Saclay, F-91191, Gif-sur-Yvette, France \\ *Corresponding author: gabi.barnes@gmail.com
}

Cement based materials are widely used as binding matrices for radionuclides in low and intermediate level waste management applications. We studied the effect of irradiation and carbonation under atmospheric condition on the leaching of $\mathrm{Sr}$ from Portland cement paste. Samples were exposed to gamma irradiation or subjected to thermal treatment under either inert or atmospheric conditions. Leaching tests were performed and supplemented by post-leaching characterization including local chemical analysis (LA-ICPMS) crystallographic analysis (XRD), and EPMA imaging. The combination of these methods enabled us to link between the crystallography, texture and composition of the treated samples and their ability to retain Sr ions. Results show that carbonation was the main factor determining the retention of Sr ions, whereas irradiation did not have a significant effect. Moreover, carbonation has a positive effect on the retention of $\mathrm{Sr}$ ions in the matrix with the formation of a carbonated zone.

3 cement paste (D), carbonation (C), radioactive waste (E), leaching, characterization (B) 
1. Introduction

27 Cement based materials are widely used in the nuclear industry for low and intermediate level waste management applications due to their availability, low cost, good chemical compatibility with waste ions and mechanical stability. The prediction of the long-term behavior of cementitious waste packages requires the identification and the understanding of degradation mechanisms that might affect the structure. One of these degradation mechanisms is water radiolysis, resulting from the immobilized radioactive waste elements, which leads to dehydration and release of $\mathrm{H}_{2}$ gas, and thus carries potential impacts on the safety of the wasteform [1,2]. Cement carbonation occurring at atmospheric conditions (in presence of $\mathrm{CO}_{2}$ ), is an additional degradation mechanism that could affect the waste-form stability [2,3]. The temperature increase induced by the irradiation could produce favorable conditions for enhanced carbonation. The extent of carbonation depends on $\mathrm{CO}_{2}$ partial pressure [4-6], moisture content in the sample pores [4,7-9] and temperature [10-12]. Although the carbonation reaction occurs in the aqueous phase and therefore slows down as water activity decreases, at highly saturated conditions the diffusion of carbon dioxide is reduced and even inhibited by water filling the pores. Therefore, carbonation occurs most rapidly at intermediate saturation of the cement paste.

There are few published data on the effect of irradiation on the immobilization of radioactive waste in cement based materials. One of the studies [2] concluded that the enhanced carbonation associated with irradiation, leads to crystallographic, textural and chemical modifications and thus affects the immobilization of radionuclides in the matrix. The effect of carbonation on the leaching resistance of cementitious pastes has been extensively studied [13-16], but contradictory results were reported. These contradictions originate from the fact that in some cases carbonation might improve waste retention either by precipitation as insoluble carbonates, or due to the reduced 
49 porosity of the carbonated matrix, while in other cases retention was reduced, possibly as a result

50 of micro-cracking due to shrinkage during carbonation or rearrangement in pore connectivity [15-

51 19].

52 The objective of this study is to gain understanding concerning the combined effect of irradiation

53 and carbonation on Sr retention in cement paste. The experimental approach included the exposure

54 of cement samples to different degradation mechanisms (irradiation and thermal treatment under

55 either inert or atmospheric conditions) followed by leaching tests. The samples were studied using

$56 \mathrm{XRD}$, to obtain their crystalline phase composition before and after treatment and leaching. LA-

57 ICP-MS and EPMA were applied to explore the local changes in the chemical composition due to

58 the various treatments, allowing the evaluation of the different treatments on the durability and

59 leaching resistivity of cementitious pastes.

60 2. Experimental

61 2.1. Sample preparation

62 The cement used for this study is a CEM I Val d'Azergues cement from Lafarge Company

63 (France). It is composed of $96 \%$ of clinker, $1 \%$ of filler and 3\% of gypsum. The chemical

64 composition of the cement is presented in Table 1. Cementitious samples were prepared with a

65 water to cement ratio (w/c) of 0.4. A non-radioactive Sr solution, using the nitrate salt, $\mathrm{Sr}\left(\mathrm{NO}_{3}\right)_{2}$

66 (Aldrich chemicals), has been added to the cement to prepare a Sr-spiked-cementitious paste, in

67 order to simulate a waste stream to be cemented, with a target Sr concentration of $3.66 \mathrm{mg} \mathrm{Sr} / \mathrm{g}$

68 paste. Non-spiked (blank) samples were prepared in order to assess the effect of the Sr addition on

69 the on the crystallography, texture and composition of the paste. 
70 All specimens were cast in plastic molds (diameter of $40 \mathrm{~mm}$ and height of $100 \mathrm{~mm}$ ) and sealed.

71 After setting, the samples were de-molded, inserted into polypropylene bags, sealed again and

72 allowed to self-cure at room temperature for 28 days. The cured specimens were sliced using a

73 diamond saw into $15 \mathrm{~mm}$ thick disc shaped samples. The list of samples is presented in Table 2.

$74 \quad 2.2$ Degradation procedures

$75 \quad 2.2 .1$ Gamma irradiation

76 Sample irradiation was performed using a ${ }^{60} \mathrm{Co}$ source in a commercial irradiation facility (Sorvan

77 Ltd, Israel). The irradiation has been performed at a dose rate of $24 \mathrm{~Gy} / \mathrm{min}$, over a period of 6

78 months, to reach a total dose of $5.0 \times 10^{6} \mathrm{~Gy}$.

79 Samples were irradiated either under inert conditions or exposed to the ambient atmospheric

80 conditions of the irradiation cell. Samples irradiated under inert conditions were placed in Pyrex ${ }^{\circledR}$

81 ampoules and sealed at sub-atmospheric pressure (500 torr) and under an Ar atmosphere. As the

82 irradiation cell lacks climate control, fluctuations in the atmospheric conditions are expected

83 during the irradiation period. The average operating temperature and the relative humidity in the

84 irradiation chamber were $\sim 40^{\circ} \mathrm{C}$ and $\sim 30 \%$, respectively.

$85 \quad 2.2 .2$ Thermal degradation

86

87 Samples exposed to thermal degradation were polished before the treatment in order to remove

88 any possible surface alteration prior to the experiment. 
89 Samples were placed inside a climatic chamber at $40^{\circ} \mathrm{C}, 32 \% \mathrm{RH}$ at atmospheric conditions for 6

90 months. Samples treated under inert conditions were placed in a reactor filled with $\mathrm{N}_{2}$ at $32 \% \mathrm{RH}$,

91 fixed by a $\mathrm{MgCl}_{2}$ saturated solution [20], inside the same climatic chamber.

92

93

94

95

96

97

98

99

100

101

102

103

104

105

106

107

108

109

\subsection{Characterization methods}

\subsubsection{XRD analysis}

Crystallographic characterization was performed using X-Ray diffraction (XRD). Measurements were carried out using a PANalytical X'Pert diffractometer $(\mathrm{Cu} \mathrm{K} \alpha, \lambda=1.54 \AA)$, on the angular range of $5^{\circ}-65^{\circ}$, in increments of $0.017^{\circ}$ or $0.033^{\circ}$.

XRD analyses were performed on bulk samples. Analysis of bulk samples eliminates a preliminary grinding and avoids possible effects of preferential orientation encountered in the powder method.

In order to obtain XRD profiles, the polished surface was analyzed, consequently a thin layer of the sample (from 30 to $150 \mu \mathrm{m}$ of thickness) was removed by polishing and the newly exposed surface was then analyzed. This method allowed us to obtain a series of diffractograms as a function of the depth of the sample. Prior to the XRD characterization, five points were marked on the bottom of the sample and the sample thickness at each of the points was measured using a micrometer screw gauge. The samples were then manually polished using 120 grit silicon carbide paper. After each polishing step, the sample thickness was measured again at each of the 5 points using the micrometer screw gauge. For each of the 5 measured points the difference between the initial thickness and the measured thickness (which refers to the measured depth) was calculated. The average of all 5 points was denoted as the sample depth analysed. Grinding was preformed up 
110 to a depth of approximately $3500 \mu \mathrm{m}$ in the sample, until reaching the non-altered part of the

111 sample.

112 XRD results were analyzed using the Reference Intensity Ratio (RIR) method [21](Johnson and 113 Zhou, 2000) which scales all diffraction data to a Corundum $\left(\mathrm{Al}_{2} \mathrm{O}_{3}\right)$ standard. The RIR factors 114 were obtained from ICSD using POWD-12++ and are presented in Table 3. The scale factors are 115 determined from the strongest intensity lines of both the analyte and corundum. In cases where the 116 calculation was performed using a different diffraction line, an additional correction factor was 117 applied, proportional to the relative intensity of the chosen diffraction line as compared to the 118 strongest diffraction line, denoted here as peak fraction.

119 Due to the presence of non-crystalline phases in the cementitious matrix, the RIR approach was 120 used as a semi-quantitative method, allowing us to normalize the diffraction intensities, and thus 121 making qualitative comparison only between the different crystalline phases in a specific sample. 122 Therefore the results are presented as intensity normalized by RIR factor and the peak fraction 123 (Table 3).

\section{$124 \quad$ 2.3.2 LA-ICPMS analysis}

125 Cement samples were cleaved, exposing a cross-section extending from the surface into the sample 126 core. Each sample was placed in a cell equipped with an inlet nozzle of $0.5 \mathrm{~mm}$ diameter. Laser

127 ablation was conducted using an ArF-excimer laser (New Wave) emitting $15 \mathrm{~ns}$ long pulses at a 128 wavelength of $193 \mathrm{~nm}$, with repetition rate of $10 \mathrm{~Hz}$, at a power of $7 \mathrm{~J} / \mathrm{cm}^{2}$, with fluence of 5.05 $129 \mathrm{~J} / \mathrm{cm}^{2}$. The cell was flushed with $0.5 \mathrm{~L} / \mathrm{min}$ helium, washing the vaporized sample into the mass 130 spectrometer. SRM NIST610 glass was used as standard. Ablation of the standard was conducted 131 at the beginning and the end of each ablation session, at a spot size of $50 \mu \mathrm{m}$. 
132 The analyzed spot size varied across the cement samples in order to attain maximal resolution near

133 the surface where leaching and precipitation are expected to have the strongest effect, and a lower

134 resolution but higher signal at inner sample areas. A spot size of $10 \mu \mathrm{m}$ was used at the outermost

$135120 \mu \mathrm{m}$ of the sample, then a spot size of $50 \mu \mathrm{m}$ was applied for the next $900 \mu \mathrm{m}$, and finally a

136 spot size of $100 \mu \mathrm{m}$ was used for the innermost $3000-4000 \mu \mathrm{m}$.

137 The ICP-MS analysis was conducted by AGILENT (7500 CX) ORS quadrupole mass 138 spectrometer with a RF power of $1500 \mathrm{~W}$, injection tube diameter of $2.0 \mathrm{~mm}$, nebulizer and 139 auxiliary gas flows of $0.9 \mathrm{~L} / \mathrm{min} \mathrm{Ar}$.

140 Table 4 lists the analyzed isotopes, the average limit of detection for the different isotopes at 141 different spot sizes and the average analytical error for the various isotopes as a function of the 142 spot size used.

143 For all three spot sizes the average error is generally lower than 3\% (except for Ba in the $10 \mu \mathrm{m}$ 144 spot size) An average error lower than $1 \%$ is obtained for all isotopes at $100 \mu \mathrm{m}$ spot size. For $145{ }^{88} \mathrm{Sr}$ and ${ }^{42} \mathrm{Ca}$, the most important analytes in this paper, the analytical error is $\leq 1 \%$.

$146 \mathrm{SiO}_{2}$ was used as an internal standard, at a concentration of $20.6 \%$ (the concentration measured in 147 the original cement powder).

$148 \mathrm{SiO}_{2}$ was used as its concentration is relatively high, thus, it is easily detected using the ICP-MS.

149 Furthermore, Si concentration is not expected to decrease significantly due to leaching effects.

150 In order to obtain coherent concentration display between all the samples, the different element 151 concentrations (C) are presented relative to the concentration of the innermost spot analyzed (C0), 152 assuming that this point resides within the undisturbed inner sample volume.

153 Figure 1 shows the normalized ${ }^{25} \mathrm{Mg}$ and ${ }^{42} \mathrm{Ca}$ signals obtained as a function of distance from the 154 surface of a leached sample, together with the analyzed spot size used. These results demonstrate 
155 that in spite of the higher limit of detection and larger error for the smaller spot size, spot size has 156 no effect on the calculated concentration of $\mathrm{Mg}$, representing an element with minimal leaching.

157 Additionally, no correlation was found between the spot size used and the concentration calculated

158 for $\mathrm{Ca}$, confirming that concentration changes are not an artifact of the spot size.

\subsubsection{EPMA (Electron Probe Micro-Analysis)}

162 Samples were impregnated in epoxy (Epofix by Struers) using a Citovac device (by Struers) for $16310 \mathrm{~min}$ at a pressure of 0.73 bar. The impregnated samples were polished parallel to the sample 164 surface using a Saphir 250 polishing machine manufactured by ATM. The samples were initially 165 polished using SiC polishing paper with 320, 600 and 1200 grid, and finally using a diamond 166 suspension of 3 and $1 \mu \mathrm{m}$. Samples were then carbon coated and mounted on the EPMA stand.

167 EPMA imaging and analyses were conducted using a JEOL 8230 superprobe EPMA with EDS 168 (Energy-Dispersive X-ray Spectroscopy) and four wavelength-dispersive spectrometers (WDS) 169 for microanalysis. Beam conditions were set to $15 \mathrm{keV}$ and $15 \mathrm{nA}$. Silicate and oxide standards 170 were used for EDS analyses. Data was processed with a PRZ correction procedure. Back-scattered 171 electron (BSE) and secondary (SEC) electron imaging were applied.

\section{$172 \quad 2.4$ Leaching experiments}

173 The leaching tests were performed according to the standard ANS-16.1 procedure [22], using 174 deionized water as the leachant. According to this procedure, the leachant volume $\left(\mathrm{cm}^{3}\right)$ equals 10 175 times the surface area of the tested sample $\left(\mathrm{cm}^{2}\right)$. Samples were immersed for 90 days, with 176 leachant replacement at predetermined leaching intervals of 2, 7, 24, 48, 72, 96, 120, 456, 1128, 
177 and 2136 hours. Following the standard procedure, the leaching tests were performed in closed

178 vessels under static, atmospheric conditions.

179 Leaching tests have been performed for samples treated under the different conditions and for 180 untreated reference samples. Duplicate samples containing Sr were tested except for the sample 181 irradiated at inert conditions, for which a single sample was available.

182 To assess the effect of initial Sr concentration on the leachability, an additional blank sample 183 prepared with no Sr doping was tested.

184 The concentrations of $\mathrm{Sr}$ and $\mathrm{Ca}$ in the leachate were determined using Inductive Coupled Plasma 185 Optical Emission Spectroscopy (SPECTRO ARCOS ICP-OES) for each leaching interval.

1863. Results

187 3.1 Crystallographic characterization of untreated HPC (hydrated Portland cement) samples

188 The powder diffraction pattern of a crushed non-treated sample (not presented) displays the typical 189 crystallographic composition for a CEM I cementitious paste: portlandite $\left(\mathrm{Ca}(\mathrm{OH})_{2}\right)$, ettringite $190\left(\mathrm{Ca}_{6} \mathrm{Al}_{2}\left(\mathrm{SO}_{4}\right)_{3}(\mathrm{OH})_{12} \cdot 26 \mathrm{H}_{2} \mathrm{O}\right)$ and $\mathrm{C}-\mathrm{S}-\mathrm{H}$ (calcium silicate hydrate phases) as hydrated phases and 191 possible presence of a small amount of calcite $\left(\mathrm{CaCO}_{3}\right)$ and some residual anhydrous phases $\left(\mathrm{C}_{4} \mathrm{AF}\right.$ 192 for $(\mathrm{CaO})_{4} \mathrm{Al}_{2} \mathrm{O}_{3} \mathrm{Fe}_{2} \mathrm{O}_{3}, \mathrm{C}_{2} \mathrm{~S}$ for $(\mathrm{CaO})_{2} \mathrm{SiO}_{2}$ and $\mathrm{C}_{3} \mathrm{~S}$ for $\left.(\mathrm{CaO})_{3} \mathrm{SiO}_{2}\right)$. As expected, no Sr bearing 193 phases have been identified by XRD analysis. 
3.2.1 Characterization of samples aged under inert conditions

196 Surface XRD analysis of samples treated under inert conditions (not presented) showed the full 197 disappearance of ettringite. Additionally, in the irradiated samples calcite was detected at the

198 surface, with a corresponding depletion of portlandite. This superficial precipitation had probably 199 occurred during sample preparation. Calcite was not found at the surface of the sample treated in 200 the climatic chamber which was polished prior to the thermal treatment (section 2.2.2).

201 EPMA imaging of a sample irradiated under inert conditions and the corresponding relative 202 concentrations of $\mathrm{Ca}, \mathrm{Ba}$ and $\mathrm{Sr}$ as obtained by LA-ICPMS are presented in Figures 2 and 3 , 203 respectively. The EPMA BSE image of the sample shows a very thin uneven front $(10-100 \mu \mathrm{m})$ at 204 the sample surface, with a denser but brighter appearance (Fig. 2), while the rest of the sample 205 remains virtually unchanged.

206 The concentration profiles of $\mathrm{Sr}, \mathrm{Ca}$, and $\mathrm{Ba}$ along a cross-section in the same sample (Fig. 3) 207 indicate a constant concentration for these three elements throughout most of the sample, except 208 for the 80-100 $\mu \mathrm{m}$ outer surface, where the concentration of all three elements shows significant 209 scatter. This scatter might reflect the uneven precipitation of a carbonate phases near the surface. 210 The precipitation of such phases is probably due to exposure to atmospheric conditions during 211 sample preparation. These results are in agreement with the formation of a thin calcite layer at the 212 sample surface as observed by XRD, and with the EPMA-BSE image showing a thin dense layer 213 at the sample surface. 
216 Samples aged under atmospheric conditions, either in the climatic chamber or during the

217 irradiation process, present similar crystallographic patterns.

218 The crystallographic composition of both samples consists of calcite near the surface of the sample

219 with corresponding disappearance of the portlandite. Further into the sample aragonite and

220 vaterite, the two metastable calcium carbonate phases, occur. The formation and stability of these

221 two phases are favored over calcite at temperatures above $40^{\circ} \mathrm{C}[23,24]$. The overall thickness of

222 the carbonated zone, defined by the presence of calcium carbonate phases, is about $3500 \mu \mathrm{m}$, for

223 both irradiated and non-irradiated samples (Fig. 4).

224 Samples treated in the climatic chamber exhibited cracking after three days of treatment (Fig. 5),

225 probably due to the enhanced drying process.

$226 \quad 3.3$ Leaching results

227 Leaching experiments were performed for samples exposed to various aging treatments as well as

228 for untreated reference samples. Figures 6 and 7 present the average cumulative fraction of Sr and

229 Ca ions leached for the different samples vs. square root of time.

230 The overall cumulative fraction values obtained for $\mathrm{Sr}$ were higher than for $\mathrm{Ca}$, although the trends

231 were similar. For the reference sample, for example, the cumulative fraction of $\mathrm{Sr}$ was five times

232 higher than for $\mathrm{Ca}$ ( 0.09 and 0.018 respectively).

233 For samples aged under atmospheric conditions, and hence exposed to carbonation, the cumulative

234 fraction of both $\mathrm{Sr}$ and $\mathrm{Ca}$ ions leached was lower than for untreated reference samples, with no 235 apparent difference between the irradiated and climatic chamber samples. 
236 The sample that has been exposed to irradiation under inert atmosphere showed a slight increase

237 in the cumulative $\mathrm{Sr}$ and $\mathrm{Ca}$ leached fraction compared with the reference sample. Significant

238 increase in the leached fraction of $\mathrm{Sr}$ and $\mathrm{Ca}$ was obtained for the samples that were treated in the

239 climatic chamber under inert atmosphere. For these samples the Sr and Ca cumulative fractions

240 increased from values of 0.09 and 0.018 in the reference sample, to values of 0.35 and 0.044 ;

241 respectively.

242 The difference between the results obtained for irradiated and climatic chamber samples treated 243 under inert atmosphere could be a result of differences in the sample pre-treatment. As presented 244 in section 3.2.1, the irradiated sample showed a thin carbonation zone. Such carbonation zone was 245 not found for the samples treated in the climatic chamber, which were polished before treatment.

246 The effect of initial Sr concentration on the Sr retention can be studied from the leaching curves 247 of the two samples irradiated under inert conditions (Fig. 8), one doped with Sr and the other 248 containing the native Sr content from CEM I cement (3660 ppm vs. 250 ppm respectively). 249 Despite the large difference in the initial $\mathrm{Sr}$ concentration the cumulative leached fractions 250 obtained were almost similar. Similar leachabilities were observed for both samples during the 251 early stages of leaching, while a slightly higher leached fraction for the sample doped with $\mathrm{Sr}$ was 252 measured at the later stages of the experiment.

253 3.4 Post leaching characterization

254 The distribution of the alkaline earth elements $\mathrm{Sr}, \mathrm{Ba}$ and $\mathrm{Ca}$ within the leached samples, as 255 obtained from LA-ICP-MS, will be presented together with the phase distribution as obtained from 256 XRD depth profile measurements and complemented with EPMA images. Sr was considered as 257 waste simulant, while $\mathrm{Ca}$ is a major cement component and $\mathrm{Ba}$ is a trace element present in cement. 
258 Both $\mathrm{Sr}$ and $\mathrm{Ba}$ may substitute $\mathrm{Ca}$ in various mineral phases (especially carbonates) with high 259 compatibility [25].

$260 \quad 3.4 .1$ Post-leaching characterization of untreated reference sample

261 The untreated sample that served as a reference for the leaching test was analyzed after leaching.

262 Figure 9 presents the EPMA BSE image of the sample. A very distinct disturbed zone can be 263 detected at the surface. This zone, which is composed of several sub-zones, has an overall thickness 264 of $700 \mu \mathrm{m}$.

265 The $\mathrm{Sr}, \mathrm{Ca}$ and $\mathrm{Ba}$ relative concentration profiles along this reference sample are presented in 266 Figure 10. All three elements show a decrease in relative concentration moving from the inner 267 undisturbed zone $\left(\mathrm{C} / \mathrm{C}_{0}=1\right)$ towards the surface of the sample.

268 For all three elements, the concentration is relatively constant along the outer $700 \mu \mathrm{m}$, except for 269 the outermost $\sim 150 \mu \mathrm{m}$, where a large dispersion of the concentrations was found. This region 270 roughly corresponds to the disturbed zone in figure 9. Further into the sample a relatively constant 271 increase in the Sr concentration, with no corresponding morphological changes in the BSE image, 272 is obtained until $\sim 1600 \mu \mathrm{m}$, where the concentration levels to $\mathrm{C} / \mathrm{C}_{0}=0.8$. A further increase in the $273 \mathrm{C} / \mathrm{C}_{0}$ is observed at $\sim 3000 \mu \mathrm{m}$ reaching the level of $\mathrm{C} / \mathrm{C}_{0}=1$ at $\sim 4000 \mu \mathrm{m}$. For both $\mathrm{Ca}$ and $\mathrm{Ba}$ the 274 concentration reaches the level of $\mathrm{C} / \mathrm{C}_{0}=1$ at $\sim 1000 \mu \mathrm{m}$.

275 Figure 11 presents the XRD profile of the same sample. At the surface, a carbonated zone is 276 detected, indicated by the presence of calcite together with a reduction in the portlandite intensity. 277 The normalized intensity for calcite is relatively high for the first $300 \mu \mathrm{m}$ from the surface of the 278 sample and then is gradually decreases up to a depth of approximately $800 \mu \mathrm{m}$ into the sample, 279 roughly corresponding to the disturbed depth as observed by EPMA (Fig. 9) and to the constant 280 concentrations of all three elements studied (Fig. 10). 
281 3.4.2 Post-leaching characterization of samples aged under inert conditions

282 Figure 12 presents an EPMA BSE image of the sample treated in the climatic chamber under inert 283 conditions. The image presents a highly porous, irregular dark area at the sample surface and along 284 two deep cracks which are perpendicular to the surface. These cracks seem to be inter-connected 285 and penetrate approximately $1000 \mu \mathrm{m}$ into the sample. The bulk of the sample contains a brighter, 286 denser looking material.

287 Figure 13 presents the element concentrations along a cross-section of the samples aged under 288 inert conditions. Both samples show relatively large scatter of all three elements within the 100 $289 \mu \mathrm{m}$ nearest to the surface, followed by a relatively constant concentration of all three elements up 290 to a depth of $500-700 \mu \mathrm{m}$.

291 Further into the sample, the Sr concentration gradually increases until reaching values similar to 292 those of the undisturbed region $\left(\mathrm{C} / \mathrm{C}_{0}=1\right)$ at a depth of about $3000 \mu \mathrm{m}$ for the irradiated sample 293 and $3800 \mu \mathrm{m}$ for the sample treated in the climatic chamber. The $\mathrm{Ca}$ and $\mathrm{Ba}$ concentration profiles 294 show a step-like increase at a depth of $700 \mu \mathrm{m}$, reaching a constant value of $\sim \mathrm{C} / \mathrm{C}_{0}=1$.

295 XRD measurements of the above samples reveal the depletion of portlandite from the outermost 296 region. Portlandite is detected at a depth of approximately 500-700 $\mu \mathrm{m}$ from the surface, in 297 accordance with the Ca concentration profile. Both samples show the presence of calcite at the 298 sample surface, gradually decreasing to a depth of approximately 500-700 $\mu \mathrm{m}$ (Fig. 14). Higher 299 intensity values of calcite were measured for the irradiated sample, in accordance with the higher 300 scatter at the surface probably due to an initial carbonation layer present in the sample, as 301 previously discussed in sections 3.2.1 and 3.3.

302 3.4.3 Post-leaching characterization of samples treated under atmospheric conditions 
303 Figure 15 presents an EPMA BSE image of the sample treated in the climatic chamber under 304 atmospheric conditions. A thin $(50-80 \mu \mathrm{m})$ porous rim is observed at the outer surface of the 305 sample. Porous regions are also observed along cracks which are perpendicular to the surface and 306 penetrate up to $300 \mu \mathrm{m}$. Beyond this porous rim, a zone of denser and brighter material, having a 307 thickness of $200 \mu \mathrm{m}$, is observed. The inner part of the sample keeps a relatively uniform 308 appearance.

309 Figure 16 presents the $\mathrm{Ca}, \mathrm{Sr}$ and $\mathrm{Ba}$ relative concentration cross section along two samples 310 exposed to atmospheric conditions, either irradiated or treated in the climatic chamber. Both 311 samples show significant scatter near the surface. For the sample treated in the climatic chamber, 312 all three elements are depleted in the outermost $100 \mu \mathrm{m}$. For the irradiated sample $\mathrm{Sr}$ and $\mathrm{Ba}$ are 313 enriched in the outermost $100 \mu \mathrm{m}$. The concentration of all three elements was found to increase 314 from a depth of $\sim 100$ to $\sim 1000 \mu \mathrm{m}$. The Ca concentration reaches its undisturbed concentration $315\left(\mathrm{C} / \mathrm{C}_{0} \sim 1\right)$ at $\sim 1000 \mu \mathrm{m}$ into the sample. For $\mathrm{Sr}$ and $\mathrm{Ba}$, however, enrichment relative to the initial 316 concentration $\left(\mathrm{C} / \mathrm{C}_{0}>1\right)$ is observed at a depth range of $700-4000 \mu \mathrm{m}$, with a gradual decrease back 317 to the undisturbed value.

318 Figure 17 presents the XRD measurements of the above samples. In both cases portlandite is 319 depleted from the surface up to a depth of 250-300 $\mu \mathrm{m}$. From this depth inward there is a gradual 320 increase in portlandite to its maximal intensity.

321 Calcite was found at the surface of both samples. Its intensity decreases towards the inner part of 322 the sample and levels off at around $300 \mu \mathrm{m}$ depth. The vaterite and aragonite phases are present 323 up to $3500 \mu \mathrm{m}$ from the surface. The intensity curves slightly differ between the two samples. 324 While for the sample treated in the climatic chamber maximal intensity for both phases was 325 detected at around 50-100 $\mu \mathrm{m}$ from the surface, for the irradiated sample both carbonate phases 
326 were not detected at the surface and appeared at a depth of $100 \mu \mathrm{m}$ with a maximal intensity around

$327150 \mu \mathrm{m}$. For both samples the normalized intensity of vaterite was higher than that of aragonite.

328 4. Discussion

329 4.1 Leaching effect - samples treated under inert conditions

330 The post-leaching reactive concentration profiles obtained for samples aged under inert 331 atmosphere, present an extended disturbed profile for all three examined elements, as compared to 332 the reference sample. This corresponds well with the higher cumulative leached fraction obtained 333 for these samples, possibly due to the formation of microcracks, which is known to occur during 334 the enhanced drying process.

335 When comparing the two samples treated under inert conditions, it can be seen that the sample 336 treated in the climatic chamber shows much higher leachability and deeper depletion profile 337 relative to the sample exposed to irradiation.

338 As already discussed in section 3.2.1, the major difference between these two samples was the 339 very thin carbonated layer present in the irradiated sample which was prior to treatment removed 340 by polishing from the sample placed in the climatic chamber. This carbonated layer, a few tens of 341 micrometers thick, may contribute to the reduced leachability of the sample irradiated under inert 342 atmosphere.

343 An additional reason for the difference between the two samples could be the increased 344 dehydration and consequent cracking due to the lower RH conditions (32\%) fixed in the climatic 345 chamber, compared to the irradiated sample sealed in an ampoule and thus exposed to much higher 346 relative humidity $(>80 \%)$. 
347 The cumulative leaching fractions of samples with different initial $\mathrm{Sr}$ concentration (3660 ppm $v s$.

$348250 \mathrm{ppm} \mathrm{Sr}$ ) were almost similar. A slightly higher leached fraction for the sample doped with $\mathrm{Sr}$,

349 may result from a higher fraction of Sr residing in the interstitial pores for the doped sample

350 relative to the non-doped one, where a higher fraction of $\mathrm{Sr}$ is probably bound within the lattice

351 sites.

352

353 4.2 Leaching effect - samples treated under atmospheric conditions

354 In the present study samples were exposed to carbonation at $40^{\circ} \mathrm{C}$ either in a climatic chamber or

355 during the irradiation process. Both samples exhibit a $\sim 3500 \mu \mathrm{m}$ thick carbonated layer, composed

356 mainly of metastable calcium carbonate phases (vaterite and aragonite). The dominance of vaterite

357 and aragonite in the carbonated layer is in agreement with previous studies showing that hexagonal

358 vaterite precipitation predominates at $40^{\circ} \mathrm{C}$, a temperature at which orthorhombic aragonite starts

359 to form as well [26]. It was further shown that a high Sr concentration enhances aragonite

360 precipitation [24,27]. Additionally Roncal-Herrero et al. [28] have shown that in the presence of

$361 \mathrm{Sr}$, vaterite can become the dominant carbonate phase even at relatively low temperatures $\left(25^{\circ} \mathrm{C}\right)$

362.

363 The $\sim 3500 \mu \mathrm{m}$ thick carbonated front leads to the reduced leachability of the Sr ions, compared to

364 the untreated sample. One possible mechanism for the reduction in ion leachability is porosity

365 clogging which is characteristic to carbonated samples $[29,30]$ as indicated by the densification of

366 the carbonated zone observed in this study (Fig 15). Furthermore, it was shown that vaterite, which

367 was found here as the dominant carbonate phase for these samples, has the lowest density among

368 these carbonate polymorphs, and therefore could lead to increased pore clogging [31]. 
369 An additional process that can lead to reduced leachability of $\mathrm{Sr}$ is the co-precipitation of $\mathrm{Sr}$ into 370 carbonate phases. Aragonite and vaterite have high coordination lattice sites for $\mathrm{Sr}$ and $\mathrm{Ba}$ and can 371 easily accommodate these larger ions [24,32]. The measured partition coefficient values for Sr in 372 aragonite is of the order of 1.1 at $40^{\circ} \mathrm{C}[33]$.

373 The effect of Sr co-precipitation in the metastable carbonate phases can be demonstrated by 374 comparing $\mathrm{Ca} / \mathrm{Sr}$ weight ratios in the cement paste and in the leachate solutions. In the original 375 cement paste the $\mathrm{Ca} / \mathrm{Sr}$ ratio is approximately 120 . However, a much lower value of 30 was 376 obtained for this ratio in the leachate of the reference sample, due to the preferential incorporation 377 of Ca into crystalline phases and the C-S-H phase, whereas the Sr remains largely interstitial and 378 more available to leaching. In the leachate of the carbonated samples the $\mathrm{Ca} / \mathrm{Sr}$ ratio is $\sim 45$, 379 indicating preferred $\mathrm{Sr}$ retention compared to the non-carbonated reference sample. This 380 emphasizes the effect of $\mathrm{Sr}$ co-precipitation in aragonite and vaterite, increasing the $\mathrm{Sr}$ retention 381 in the paste and thus reducing its relative leachability.

382 Therefore we may conclude that the clogging effect, which is expected to affect equally all ion 383 mobilities and not to change the $\mathrm{Ca} / \mathrm{Sr}$ ratio, is secondary in this case.

384 Additional evidence to the increased Sr retention induced by co-precipitation in aragonite and 385 vaterite phases can be observed by the analysis of the solid matrix. The $[\mathrm{Sr}] /[\mathrm{Sr}]_{0}$ ratio within an 386 unleached sample is $\sim 1$ throughout the sample, with the exception of the outer surface zone where 387 a large scatter in the results was detected (see section 4.4). All the leached samples that were treated 388 under inert conditions as well as the reference sample show a decrease in the $[\mathrm{Sr}] /[\mathrm{Sr}]_{0}$ ratio from 389 a value of 1 in the undisturbed zone to a lower value towards the surface. However, in the samples 390 treated under atmospheric conditions a local enrichment in the $[\mathrm{Sr}] /[\mathrm{Sr}]_{0}$ ratio is measured within 391 the aragonite/vaterite precipitation zone, where this ratio reaches the range of $1.2-1.4$ (Fig. 16). 
392 The relative enrichment of $\mathrm{Ba}$ in the carbonated front may be related to a similar process occurring 393 due to preferred Ba precipitation in aragonite [34].

394 It is suggested that this enrichment has occurred during the initial carbonation process. 395 Vaterite/aragonite precipitation during the treatment has reduced the local $\mathrm{Sr}$ concentration in the 396 pore solution, creating a local gradient in $\mathrm{Sr}$ concentration and thus yielding a driving force for $\mathrm{Sr}$ 397 diffusion from the surrounding areas to the carbonate precipitation zone. Continuous precipitation 398 of $\mathrm{Sr}$ and $\mathrm{Ba}$ caused the observed relative enrichments, and thus increased the $\mathrm{Sr}$ and $\mathrm{Ba}$ ions 399 retention within the sample.

400 It is interesting to note that although the sample carbonated in the climatic chamber showed 401 evidence of cracking at an early stage of the treatment (Fig. 5), this cracking did not lead to higher 402 Sr leachability, supporting the suggestion that $\mathrm{Sr}$ immobilization is dominated by its enhanced co403 precipitation in the carbonated layer.

$404 \quad 4.3$ The calcite surface layer effect

405 In the analyzed unleached sample, the relative concentration of $\mathrm{Ca}, \mathrm{Sr}$ and $\mathrm{Ba}$ at the outer surface 406 layer showed a large scatter with values ranging between 0.6 and 1.4 (Fig. 3). We suggest that this 407 phenomenon is related to calcite precipitation during sample handling at atmospheric conditions, 408 creating a very thin $(10-100 \mu \mathrm{m})$ carbonated layer.

409 Additionally, in all leached samples, either treated or untreated, a calcite layer was detected at the 410 outer surface of the sample with thickness varying between 100-500 $\mu \mathrm{m}$.

411 Calcite precipitation during leaching is reflected in the leaching curves where a change in the slope 412 develops over the square root of time (Figures $6 \& 7$ ). A steeper slope was measured over the first 4137 days of leaching, whereas a more moderate slope persists over the remaining leaching process. 
414 This effect was clearly demonstrated for the samples treated in the climatic chamber which have 415 been polished before treatment and therefore they were lacking the initial calcite layer, making the 416 effect more pronounced. This behavior is typical to the formation of a dense impervious 417 carbonation layer and is consistent with previous results by Andac and Glasser [31]. Various other 418 studies investigating the leaching of Portland cement pastes by hydrogeno-carbonate solutions $419[35,36]$ or natural waters containing $\mathrm{CO}_{2}[37,38]$ have shown the formation of a calcite crust, at or 420 near the paste-leachant interface, which strongly slows down the degradation process.

421 Within the near surface calcite layer significant scatter of the $\mathrm{Ca}, \mathrm{Sr}$ and $\mathrm{Ba}$ concentrations occurs. 422 When observing the chemical composition of this layer in leached samples under all treatments, $423 \mathrm{Ca}$ and $\mathrm{Sr}$ usually show a reduction in their relative concentration, whereas Ba shows a significant 424 increase in its relative concentration (Figures 10,13\&16)

425 The reason for this different behavior is related to the two simultaneous processes of leaching and 426 calcite precipitation. $\mathrm{Ca}$, as a major element, is effectively leached from the sample. Due to its 427 high concentration in the matrix, the small amount of calcite precipitated does not affect the overall 428 trend of the reduction in the Ca relative concentration.

429 On the other hand, $\mathrm{Ba}$, being a trace element is significantly affected from minor precipitation 430 processes. The relatively high $\mathrm{Ba}$ enrichment with respect to $\mathrm{Sr}$ is mainly the outcome of its lower 431 concentration in the paste and hence higher sensitivity to precipitation processes. This 432 phenomenon is widely used in geological studies, where trace elements are used to emphasize the 433 precipitation of crystalline phases [39].

434 Moreover, the magnitude of this scatter for all three elements is much smaller for the samples 435 treated in the climatic chamber (Fig. 13a) compared with the irradiated samples (Fig. 13b). This is 
436 probably the consequence of the presence of the pre-leaching calcite layer in the later increasing

437 the relative amount of calcite in the sample surface and therefore leading to higher scatter in the 438 element concentrations.

439 5. Conclusions

440 The use of local chemical analysis (LA-ICP-MS) together with crystallographic analysis (XRD), 441 supplemented by EPMA imaging, enabled us to link between the crystallography, texture and the 442 composition of the treated samples and their ability to retain $\mathrm{Sr}$ ions in the system.

443 The cementation process is used for the conditioning of low and intermediate level radioactive 444 waste; hence, the effects of irradiation and carbonation are intrinsic to the assessment of the 445 process. However, in the present study no evidence of enhanced degradation mechanisms due to 446 irradiation was found. Carbonation on the other hand, had shown a positive effect on the retention 447 of Sr ions in the matrix with the formation of a distinct carbonated zone at the surface.

448 In the present study carbonation occurred in three different manners. 1) A very thin (up to $100 \mu \mathrm{m}$ ) 449 carbonated zone was formed during sample preparation and handling. This thin calcite layer was 450 removed for the samples treated in the climatic chamber, leading to an increased Sr leachability 451 compared to samples which were not polished before treatment. 2) All samples exhibited some 452 carbonation $(100-500 \mu \mathrm{m})$ during the leaching test, performed according to the ANSI-16.1 453 procedure with no precaution taken to avoid exposure to the atmosphere. 3) For all samples 454 exposed to enhanced carbonation at $40^{\circ} \mathrm{C}$, a $3500 \mu \mathrm{m}$ thick carbonated layer, composed of 455 metastable calcium carbonates (aragonite and vaterite) was formed. These carbonate phases 
456 possess high coordination lattice sites for $\mathrm{Sr}(\mathrm{and} \mathrm{Ba})$ and therefore can easily accommodate these

457 larger ions [32,24].

458 The crystallographic and chemical composition of the samples as well as the retention of Sr ions

459 (representing the immobilized waste) was highly influenced by the latter carbonation process. The

460 extent of carbonation, as well as the crystallography and the Sr retention were similar for both

461 carbonated samples with no additional effect found for the irradiated sample. Thus, carbonation

462 enhanced by temperature increase, is sufficient to explain the retention behavior of strontium under

463 the present atmospheric conditions. The correlation found between relative $\mathrm{Sr}$ enrichment and the

464 presence of Ca-carbonate phases, clearly leads to the conclusion that during the carbonation

465 treatment Sr ions are preferentially fractionated into these metastable carbonate phases, leading to

466 a higher retention in the cement paste.

467 References

468 [1] C. Gallé, H. Peycelon, P. Le Bescop, S. Bejaoui, V. L'Hostis, B. Bary, P. Bouniol, C. Richet,

469 Concrete long term behavior in the context of nuclear waste management: Experimental and

470 modeling research strategy, Journal of Physics IV - Proceedings. 136 (2006) 25-38.

471 [2] G. Bar-Nes, A. Katz, Y. Peled, Y. Zeiri, The combined effect of radiation and carbonation on

472 the immobilization of $\mathrm{Sr}$ and $\mathrm{Cs}$ ions in cementitious pastes, Materials and Structures 41, (2008)

$473 \quad 1563-1570$.

474 [3] F. Vodák, V. Vydra, K. Trtik, O. Kapickova, Effect of gamma irradiation on properties of 475 hardened cement paste, Materials and Structures. 44 (2011) 101-107. 
476 [4] V.G. Papadakis, C.G. Vayenas, M.G. Fardis, Fundamental modeling and experimental

477 investigation of concrete carbonation, ACI Materials Journal. 88(4) (1991) 363-373.

478 [5] H. Hyvert, A. Sellier, F. Duprat, P. Rougeau, P. Francisco, Dependency of C-S-H

479 carbonation rate on $\mathrm{CO} 2$ pressure to explain transition from accelerated tests to natural

480 carbonation, Cement and Concrete Research. 40, (2010) 1582-1589.

481 [6] M. Castellote, L. Fernandez, C. Andrade, C.Alonso C., Chemical changes and phase analysis

482 of OPC pastes carbonated at different CO2 concentrations, Materials and Structures. 42 (2009)

$483 \quad 515-525$.

484 [7] G.J. Verbeck 1958 Carbonation of hydrated Portland cement, Am Soc Test Mater. 205, 485 (1958) 17-36.

486 [8] H. Wierig, Longtime studies on the carbonation of concrete under normal outdoor exposure, 487 Proc. of RILEM seminar on the durability of concrete structures under normal outdoor exposure, 488 Hannover, Germany, (1984) 239-249.

489 [9] I. Galan, C. Andrade, M. Castellote, Natural and accelerated CO2 binding kinetics in cement 490 paste at different relative humidities, Cement and Concrete Research. 49 (2013) 21-28.

491 [10] Mori et al. 1972 On carbonation of Portland blast-furnace slag cement concrete, 492 Proceedings of the 26th general meeting of the Cement Association of Japan, Tokyo, 184-188.

493 [11] T. Uomoto, Y. Takada, Factors affecting concrete carbonation ratio, Concrete Library of 494 JSCE 21, (1993) 31-44. 
495 [12] E. Drouet, S. Poyet, P. Le Bescop, J.M. Torrenti, J M, Chemical changes and carbonation 496 profiles of carbonated cement pastes at $80^{\circ} \mathrm{C}$ for different relative humidities, Proceedings of 497 CONSEC'10, 2010, Merida, Mexico.

498 [13] A.C. Garrabrants, F. Sanchez, D.S. Kosson, Changes in constituent equilibrium leaching 499 and pore water characteristics of a Portland cement mortar as a result of carbonation, Waste 500 Management, 24(1) (2004) 19-36.

501 [14] J.C. Walton, M.S.Bin Shafique, R.W. Smith, N. Gutierrez, A.J. Tarquin, Role of 502 carbonation in transient leaching of cementitious wasteforms, Environmental Science and 503 Technology. 31 (1997) 2345-2349.

504 [15] T. Van Gerven, D. Van Baelen, V. Dutre, C. Van de casteele, Influence of carbonation and 505 carbonation methods on leaching of metals from mortars, Cement and Concrete Research. 34 506 (2004) 149-156.

507 [16] M.S. Bin Shafique, J.C. Walton, N. Gutierrez, R.W. Smith, A.J. Tarquin, Influence of 508 carbonation on leaching of cementitious wasteforms, Journal of Environmental Engineering 509 (ASCE). 124 (1998) 463-467.

510 [17] P.H.R. Borges, J.O. Costa, N.B. Milestone, C.J. Lynsdale, R.E. Streatfield, Carbonation of $511 \mathrm{CH}$ and $\mathrm{C}-\mathrm{S}-\mathrm{H}$ in composite cement pastes containing high amounts of BFS, Cement and 512 Concrete Research. 40 (2013) 284-292. 
513 [18] J. Han, W. Sun, G. Pan, W. Caihui, Monitoring the evolution of accelerated carbonation of 514 hardened cement pastes by x-ray computed tomography, Journal of Materials in Civil Engineering. $515 \quad 25(2013) 347-354$.

516 [19] M. Auroy, S. Poyet, P. Le Bescop, J.M. Torrenti, T. Charpentier, M. Moskura, X. Bourbon, 517 Impact of carbonation on unsaturated water transport properties of cement-based materials, 518 Cement and Concrete Research. 74 (2015) 44-58.

519 [20] L. Greenspan, Humidity fixed points of binary saturated aqueous solutions, Journal of 520 Research of the National Bureau of Standards - A. Physics and Chemistry. 81A (1977) 89-96.

521 [21] Q. Johnson, R.S. Zhou, Checking and estimating RIR values, JCPDS-International Centre 522 for Diffraction Data, Advances in X-ray Analysis. 42 (2000) 287-296.

523 [22] ANSI/ANS-16.1-1986 (1986) Measurement of the leachability of solidified low-level 524 radioactive wastes by a short term test procedure. American Nuclear Society, IL, USA

525 [23] T. Ogino, T. Suzuki, K. Sawada, The formation and transformation mechanism of calcium 526 carbonate in water, Geochimica and Cosmochimica Acta. 51(10) (1987) 2757-2767.

527 [24] J.L. Wray, F. Daniels, Precipitation of Calcite and Aragonite, Journal of the American 528 Chemical Society. 79(7) (1957) 2031-2034.

529 [25] M.L.D. Gougar, B.E. Scheetz, D.M. Roy, Ettringite and C-S-H Portland Cement Phases for 530 Waste Ion Immobilization: A Review. Waste Management. 16(4) (1996) 295-303. 
531 [26] E.T. Stepkowska, J.L. Pérez-Rodríguez, M.J. Sayagués, J.M. Martínez-Blanes, Calcite, 532 Vaterite and Aragonite forming on cement hydration from liquid and gaseous phase, Journal of 533 Thermal Analysis and Calorimetry. 73 (2003) 247-269.

534 [27] I. Sunagawa, Y. Takahashi, H. Imai, Strontium and aragonite-calcite precipitation, J. 535 mineralogical and petrological sciences. 102 (2007) 174-181.

536 [28] T. Roncal-Herrero, J.D. Rodriguez-Blanco, P. Bots, S. Shaw, L.G. Benning, The Role of $537 \mathrm{Zn}, \mathrm{Sr}, \mathrm{Mg}$ and PO4 in the Interaction of Carbonate-Rich Waters with Sulphate Minerals, revista 538 de la sociedad española de mineralogía. 15 (2011) 181.

539 [29] V.T. Ngala, C.L. Page, Effects of carbonation on pore structure and diffusional properties of 540 hydrated cement pastes, Cement and Concrete research. 27(7) (1997) 995-1007.

541 [30] P. A. Claisse, H. El-Sayad, I.G. Shaaban, Permeability and pore volume of carbonated 542 concrete, ACI Materials Journal. 96 (3) (1999) 378-382.

543 [31] M. Andac \& F.P. Glasser, Long-Term leaching mechanisms of Portland cement-stabilized 544 municipal solid waste fly ash in carbonated water, Cement and Concrete Research. 29 (1999) 545 179-186.

546 [32] J.L. Banner, Application of the trace element and isotope geochemistry of strontium to 547 studies of carbonate diagenesis, Sedimentology. 42 (1995) 805-824.

548 [33] D.J.J. Kinsman, H.D. Holland, The co-precipitation of cations with CaCO3-IV. The co549 precipitation of $\mathrm{Sr}^{+2}$ with aragonite between $16^{\circ}$ and $96^{\circ} \mathrm{C}$, Geochim. Cosmochim. Acta. 33 550 (1969) 1-17. 
551 [34] M. Dietzel, N. Gussone, A. Eisenhauer, Co-precipitation of $\mathrm{Sr}^{2+}$ and $\mathrm{Ba}^{2+}$ with aragonite by

552 membrane diffusion of CO2 between 10 and $50^{\circ} \mathrm{C}$, Chemical geology. 203 (2004) 139-151.

553 [35] Badouix et al. 1999 Toward a validation of the modeling of concrete long term alteration by 554 natural water attack. Global proceedings

555 [36] I. Kurashige, M. Hironaga, K. Niwase, Effects of hydrogencarbonate and chloride in ground 556 water on leaching of cementitious materials. CONSEC'07 Tours, (2007) 615-622.

557 [37] J. Cowie, F.P. Glasser, The reaction between cement and natural waters containing 558 dissolved carbon dioxide, Advanced in Cement Research. 4 (1992) 119-134.

559 [38] A. Dauzères, P. Le Bescop, P. Sardini, C. Cau Dit Coumes, Study of CEMI and low pH

560 cement pastes leaching in multi-ionic underground water. CONSEC'10 Mérida, (2010) 495-503

561 [39] Winter J.D., An introduction to igneous and metamorphic petrology, 2001, Prentice Hall.

563 Funding: This work was supported by the Israel Atomic Energy Commission (IAEC) and the 564 French Alternative Energies and Atomic Energy Commission (CEA). 
569 Table 1: Chemical composition of CEM I Val d'Azergues cement (wt\%) (Producers data)

\begin{tabular}{llllllllllll}
\hline $\mathrm{SiO}_{2}$ & $\mathrm{Al}_{2} \mathrm{O}_{3}$ & $\mathrm{Fe}_{2} \mathrm{O}_{3}$ & $\mathrm{CaO}$ & $\mathrm{MgO}$ & $\mathrm{K}_{2} \mathrm{O}$ & $\mathrm{Na}_{2} \mathrm{O}$ & $\mathrm{SO}_{3}$ & $\mathrm{~S}^{2}$ & $\mathrm{Cl}^{-}$ & $\mathrm{P}_{2} \mathrm{O}_{5}$ & LOI \\
\hline 20.6 & 3.6 & 5.0 & 64.3 & 0.7 & 0.7 & 0.2 & 2.7 & 0.01 & 0.06 & 0.4 & 1.1 \\
\hline
\end{tabular}

570

571

572

573

574

575

576

577

578

579

580

581

582 
584 Table 2: List of samples (irradiation $=\mathrm{IR}$, climatic chamber $=\mathrm{CC}$, atmospheric=At, inert $=\mathrm{In}$ )

\begin{tabular}{|c|c|c|c|c|c|c|}
\hline $\begin{array}{l}\text { Sample } \\
\text { experimental } \\
\text { condition }\end{array}$ & Sr doping & $\begin{array}{l}\text { Polished } \\
\text { before } \\
\text { treatment }\end{array}$ & Treatment & $\begin{array}{l}\text { External } \\
\text { conditions }\end{array}$ & leaching & comments \\
\hline Reference & + & - & - & - & + & \\
\hline $\begin{array}{l}\text { Climatic chamber } \\
\text { atmospheric }\end{array}$ & + & + & $\mathrm{CC}$ & At & + & \\
\hline $\begin{array}{l}\text { Climatic chamber } \\
\text { inert }\end{array}$ & + & + & $\mathrm{CC}$ & In & + & \\
\hline $\begin{array}{l}\text { Irradiated } \\
\text { atmospheric }\end{array}$ & + & - & IR & At & + & \\
\hline $\begin{array}{l}\text { Irradiated inert } \\
\text { (blank) }\end{array}$ & - & - & IR & In & + & $\begin{array}{l}\text { Natural } \mathrm{Sr} \\
\text { concentration }\end{array}$ \\
\hline $\begin{array}{l}\text { Irradiated inert } \\
\text { (unleached) }\end{array}$ & + & - & IR & In & - & \\
\hline
\end{tabular}


591

592 Table 3: Crystallographic data for the XRD RIR analysis (from ICSD using POWD-12++)

\begin{tabular}{|l|l|l|l|}
\hline mineral & $2 \theta$ & RIR & peak fraction \\
\hline Calcite & 29.3 & 3.2 & 1 \\
\hline Aragonite & 26.1 & 1.13 & 1 \\
\hline Vaterite & 26.9 & 1.14 & 1 \\
\hline Portlandite & 17.9 & 3.46 & 0.74 \\
\hline
\end{tabular}

593

594

595

596

597

598

599

600

601

602 
604 Table 4: List of analyzed isotopes, their average limit of detection and average analytical error 605 percent for the different spot sizes

606

\begin{tabular}{|c|c|c|c|c|c|c|}
\hline $\begin{array}{l}\text { Spot } \\
\text { size }\end{array}$ & $10 \mu \mathrm{m}$ & & $50 \mu \mathrm{m}$ & & $100 \mu \mathrm{n}$ & \\
\hline & $\begin{array}{l}\text { LOD } \\
(\mu \mathrm{g} / \mathrm{g})\end{array}$ & $\%$ error & $\begin{array}{l}\text { LOD } \\
(\mu \mathrm{g} / \mathrm{g})\end{array}$ & $\%$ error & $\begin{array}{l}\text { LOD } \\
(\mu \mathrm{g} / \mathrm{g})\end{array}$ & $\%$ error \\
\hline${ }^{25} \mathrm{Mg}$ & 76 & 2.4 & 2.7 & 0.6 & 0.9 & 0.2 \\
\hline${ }^{29} \mathrm{Si}$ & 3083 & 1.7 & 111 & 0.4 & 29 & 0.1 \\
\hline${ }^{42} \mathrm{Ca}$ & 3696 & 1.0 & 94 & 0.1 & 26 & 0.1 \\
\hline${ }^{43} \mathrm{Ca}$ & 1653 & 1.5 & 68 & 0.3 & 24 & 0.1 \\
\hline${ }^{88} \mathrm{Sr}$ & 1.4 & 0.8 & 0.1 & 0.2 & 0.02 & 0.1 \\
\hline${ }^{137} \mathrm{Ba}$ & 7.3 & 8.1 & 0.4 & 1.9 & 0.1 & 0.8 \\
\hline
\end{tabular}

607

608

609

610

611

612 


\section{Figure captions:}

615 Figure 1: The sampling spot size and relative concentration of $\mathrm{Ca}$ and $\mathrm{Mg}$ as a function of the 616 distance from the sample surface in a leached sample. $\mathrm{C}=$ the concentration at a specific distance, $617 \mathrm{C}_{0}=$ the concentration at the undisturbed inner sample volume.

618 Figure 2: EPMA BSE image of sample surface irradiated under inert atmosphere.

619 Figure 3: Relative concentration of $\mathrm{Ca}, \mathrm{Ba}$ and $\mathrm{Sr}$ as obtained by LA-ICPMS along a cross section in a 620 sample irradiated under inert conditions

621 Figure 4: XRD profiles of samples treated under atmospheric conditions. (a) sample treated in 622 climatic chamber, (b) sample irradiated

623 Figure 5: Cracking on sample exposed to atmospheric conditions in the climatic chamber

624 Figure 6: Sr Cumulative fraction as a function of square root of leaching time. The error bars 625 represent the average deviation of duplicate samples.

626 Figure 7: Ca Cumulative fraction as a function of square root of leaching time. The error bars 627 represent the average deviation of duplicate samples

628 Figure 8: Sr Cumulative fraction for samples irradiated under inert conditions doped and un-doped 629 with $\mathrm{Sr}$ as a function of square root of leaching time.

630 Figure 9: EPMA BSE image of the untreated reference leached sample

631 Figure 10: the $\mathrm{Sr}, \mathrm{Ca}$ and $\mathrm{Ba}$ concentration variation along a cross section in the

632 untreated reference leached sample

633 Figure 11: XRD profile of the untreated reference leached sample 
634 Figure 12: EPMA BSC image of leached sample after treatment in the climatic chamber under 635 inert atmosphere.

636 Figure 13: LA-ICP-MS Ca, Ba and Sr concentration variation along a cross section in the two

637 leached samples after treatment under inert atmosphere.(a) climatic chamber (b) irradiated

638 Figure 14: Phase distribution along a cross section in the leached samples after treatment under

639 inert atmosphere (a) in the climatic chamber (b) irradiated

640 Figure 15: EPMA BSE images of leached sample treated in the climatic chamber under 641 atmospheric conditions. Zoom into the near edge area (surface on the top).

642 Figure 16: The $\mathrm{Ca}, \mathrm{Ba}$ and $\mathrm{Sr}$ concentrations along a cross section in leached samples after

643 treatment under atmospheric conditions; (a) in the climatic chamber (b) irradiated

644 Figure 17: Phase distribution along a cross section in the leached samples after treatment under 645 atmospheric conditions (a) in the climatic chamber (b) irradiated

646

647

648

649

650

651

652

653

654 


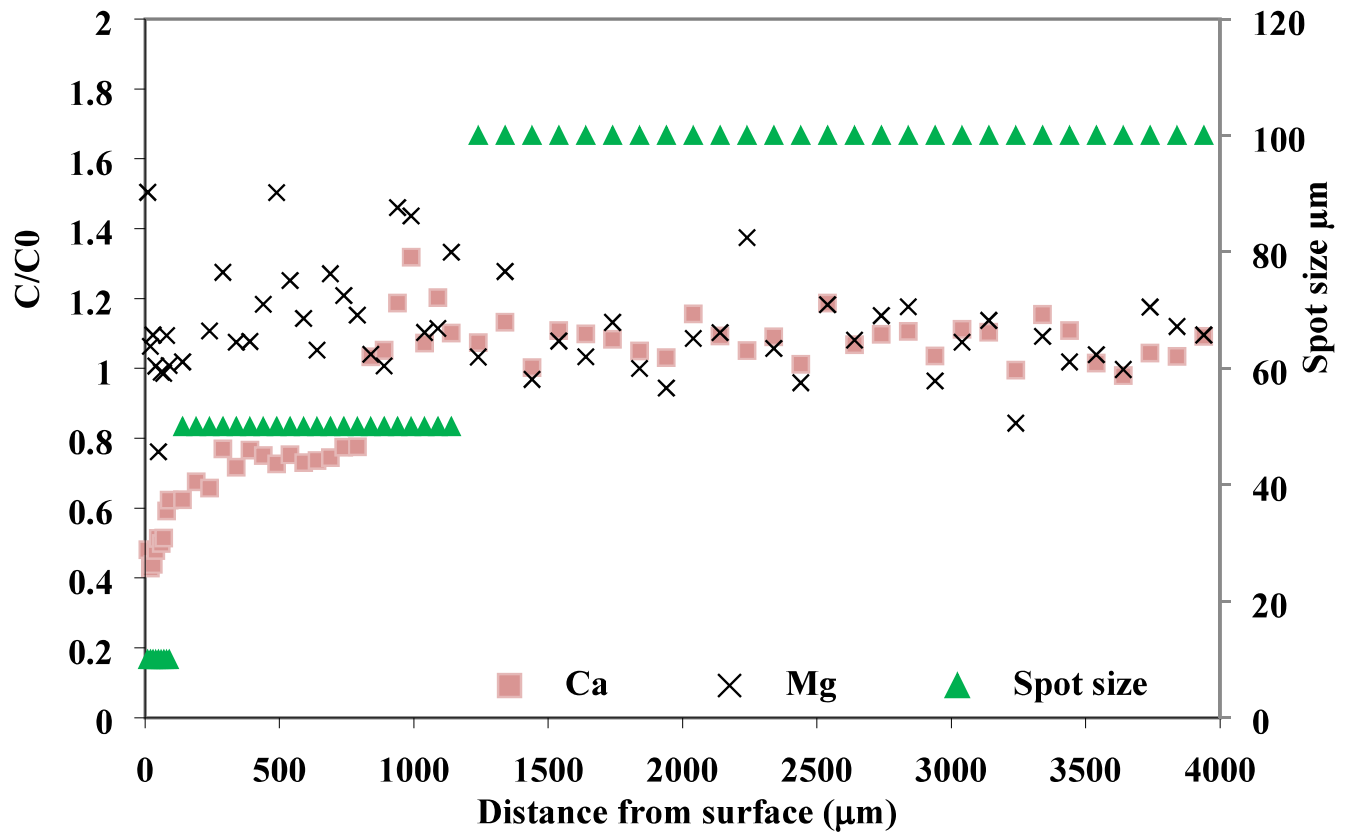

Figure 1: The sampling spot size and relative concentration of $\mathrm{Ca}$ and $\mathrm{Mg}$ as a function of the distance from the sample surface in a leached sample. $\mathrm{C}=$ the concentration at a specific distance, $\mathrm{C}_{0}=$ the concentration at the undisturbed inner sample volume. 


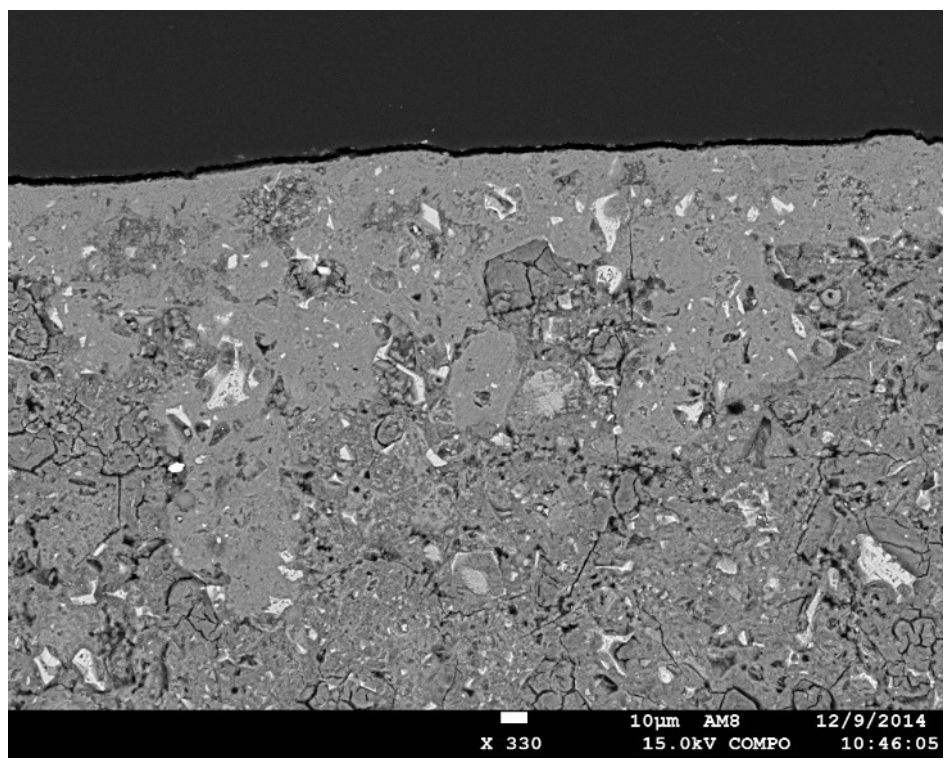

Figure 2: EPMA BSE image of sample surface irradiated under inert atmosphere. 


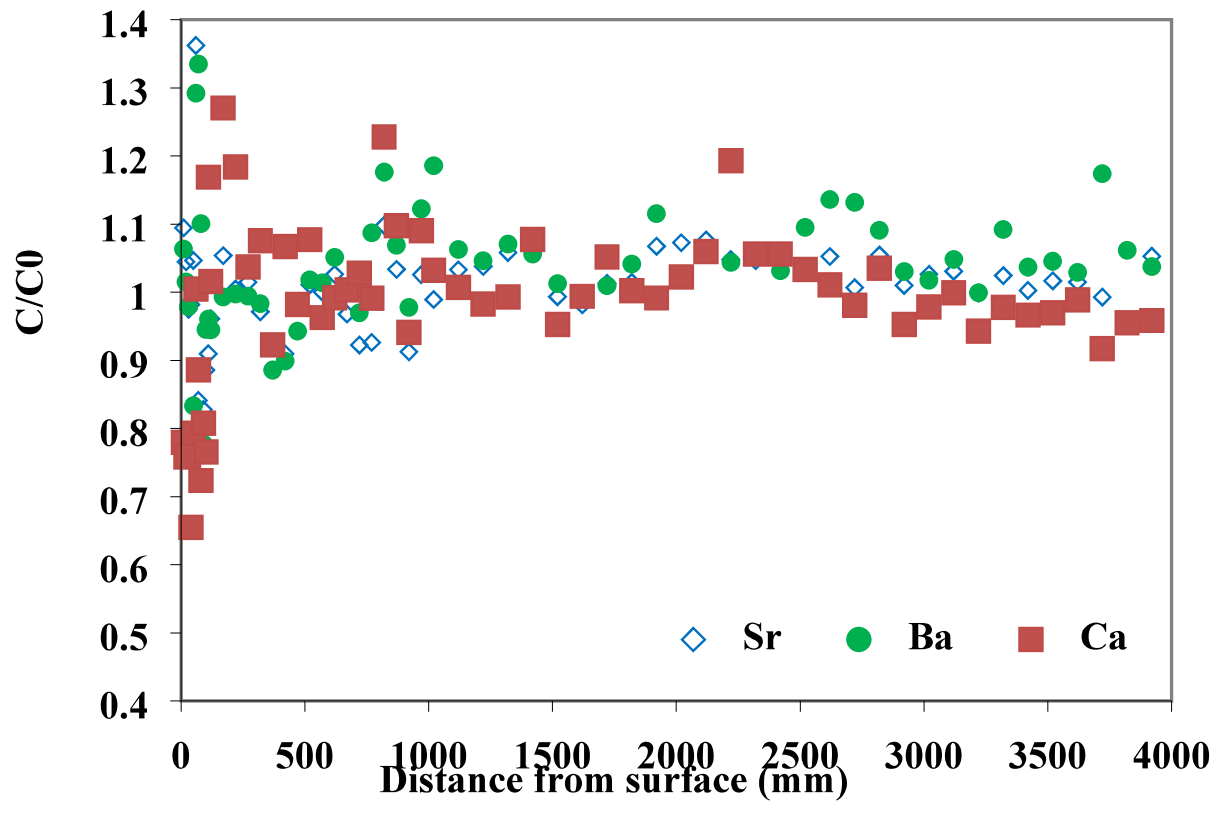

Figure 3: Relative concentration of $\mathrm{Ca}, \mathrm{Ba}$ and $\mathrm{Sr}$ as obtained by LA-ICPMS along a cross section in a sample irradiated under inert conditions 

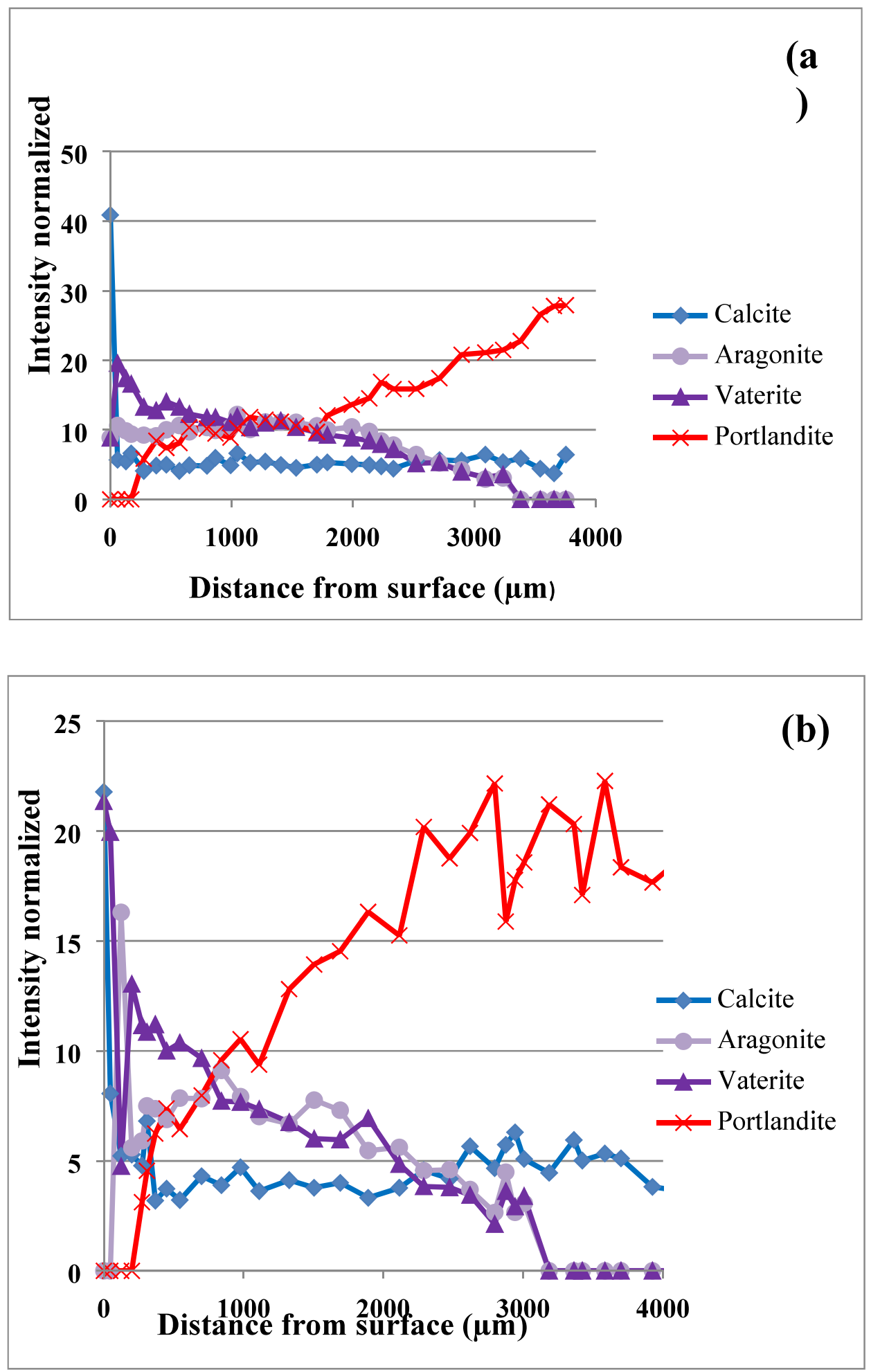

Figure 4: XRD profiles of samples treated under atmospheric conditions. (a) sample treated in climatic chamber, (b) sample irradiated 


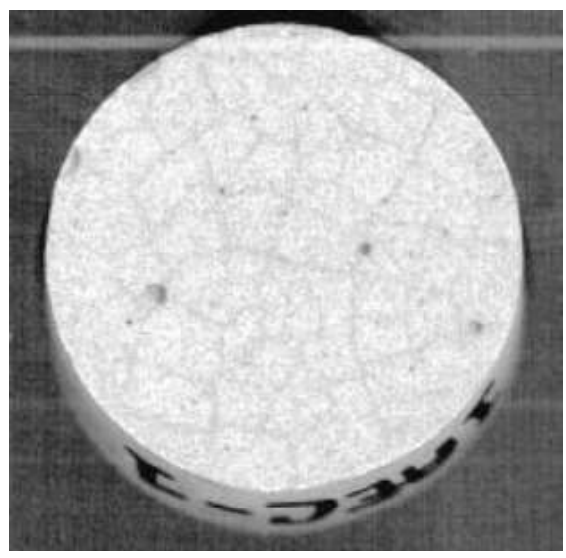

Figure 5: Cracking on sample exposed to atmospheric conditions in the climatic chamber 


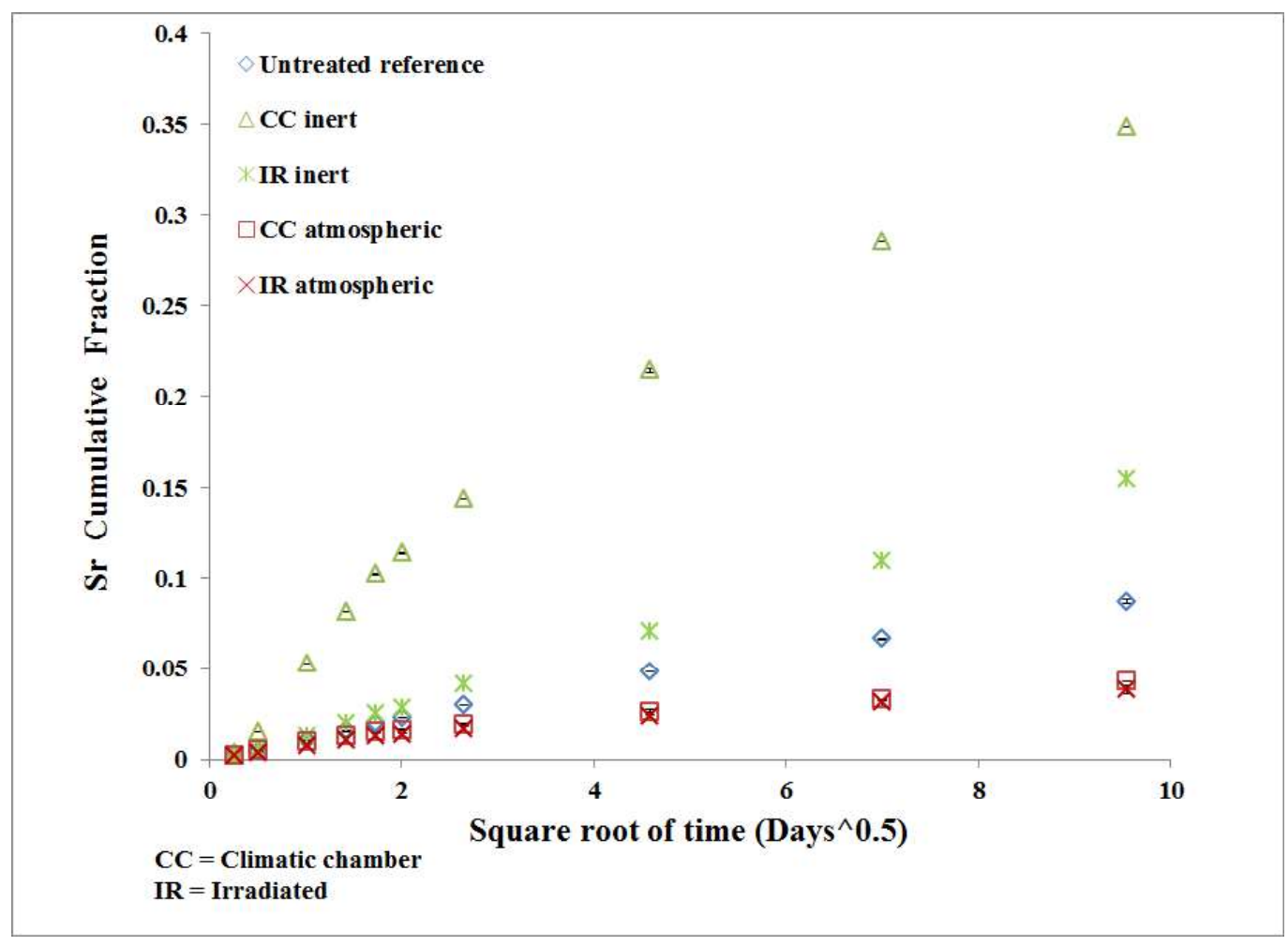

Figure 6: Sr Cumulative fraction as a function of square root of leaching time. The error bars represent the average deviation of duplicate samples. 


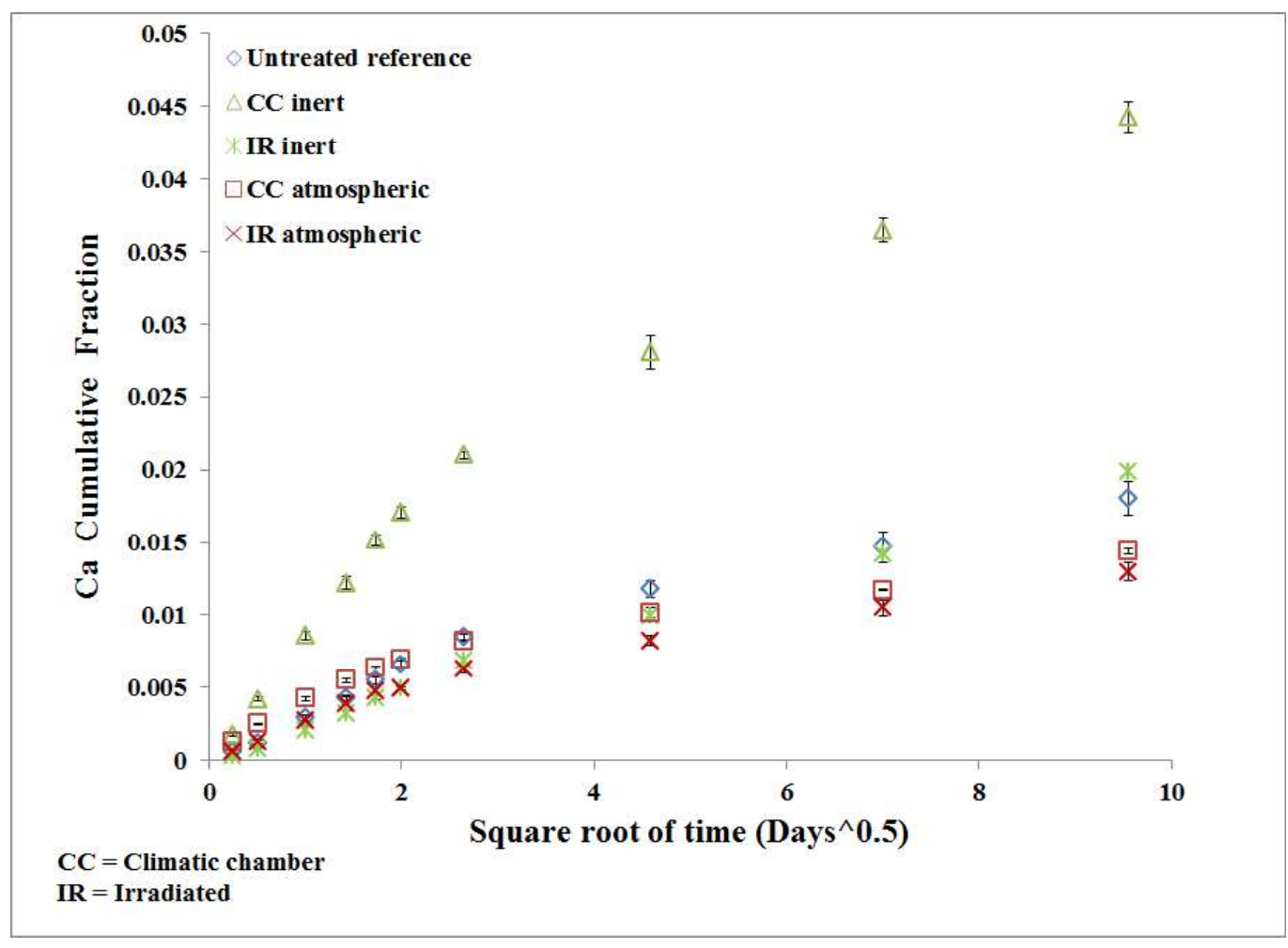

Figure 7: Ca Cumulative fraction as a function of square root of leaching time. The error bars represent the average deviation of duplicate samples 


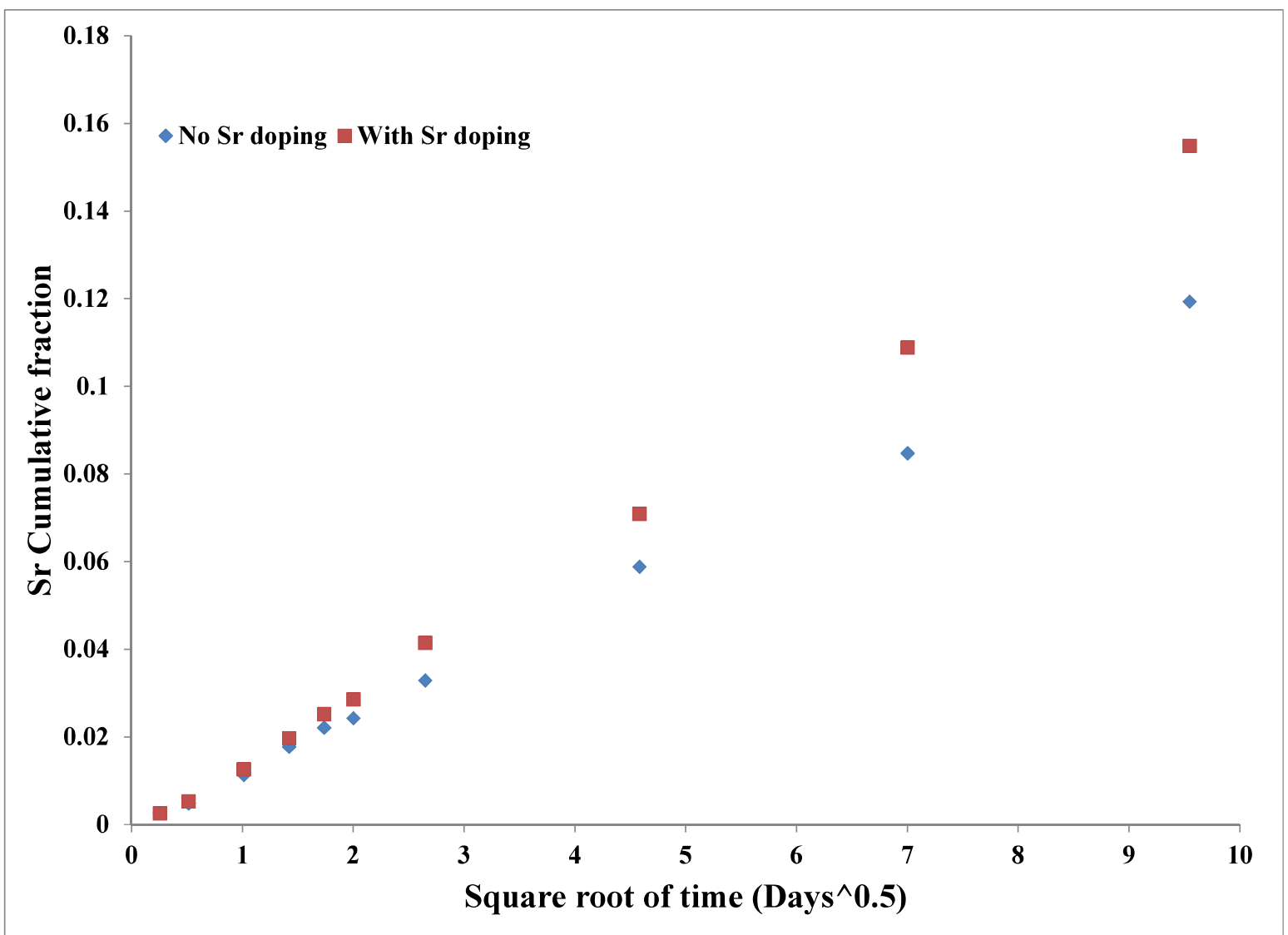

Figure 8: Sr Cumulative fraction for samples irradiated under inert conditions doped and un-doped with $\mathrm{Sr}$ as a function of square root of leaching time. 


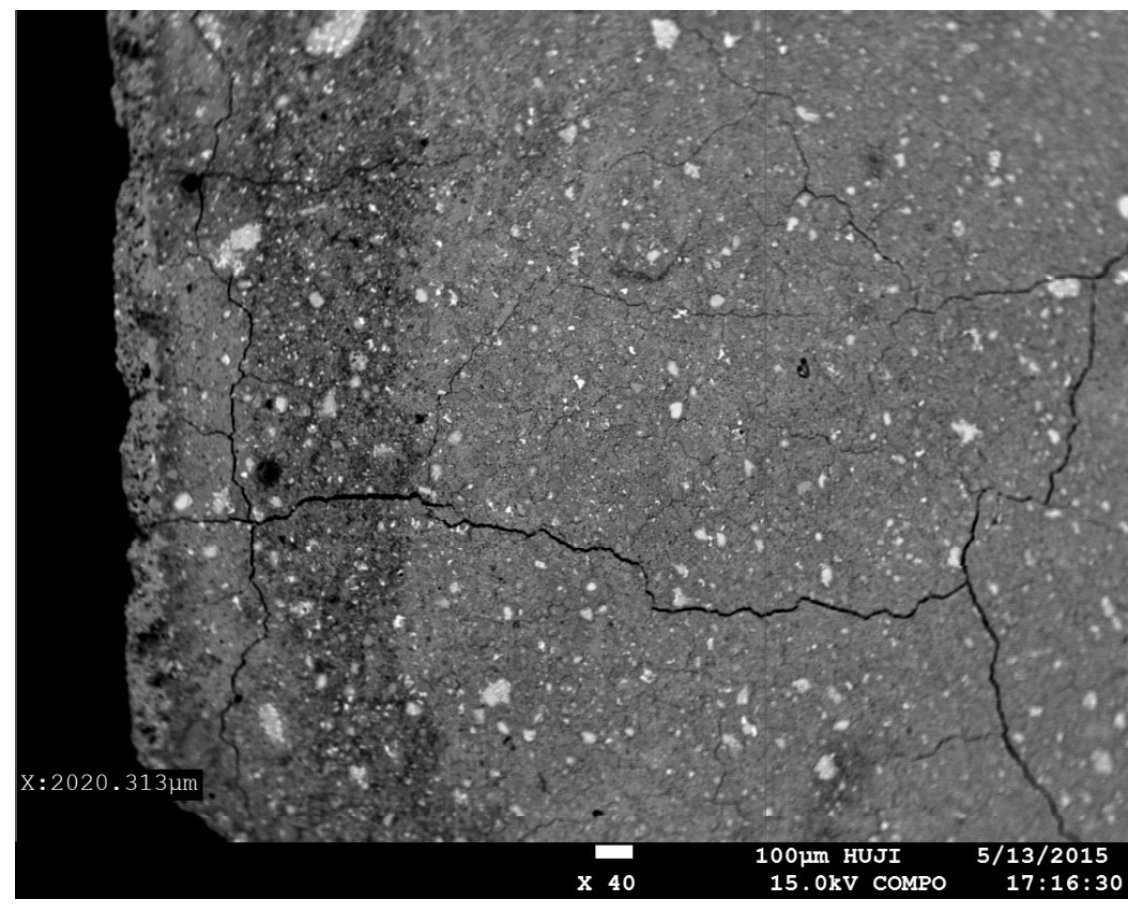

Figure 9: EPMA BSE image of the untreated reference leached sample 


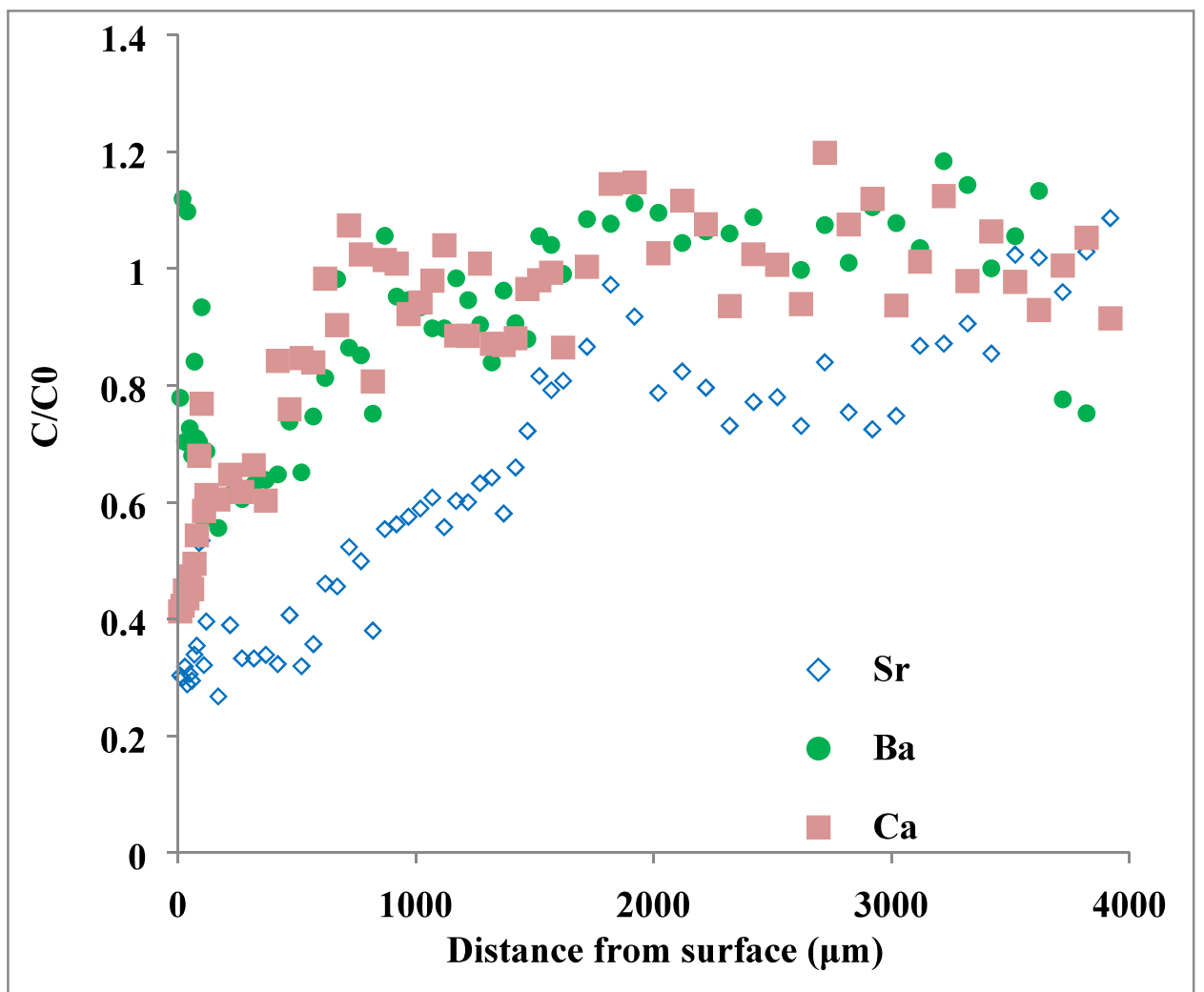

Figure 10: the $\mathrm{Sr}, \mathrm{Ca}$ and $\mathrm{Ba}$ concentration variation along a cross section in the untreated reference leached sample 


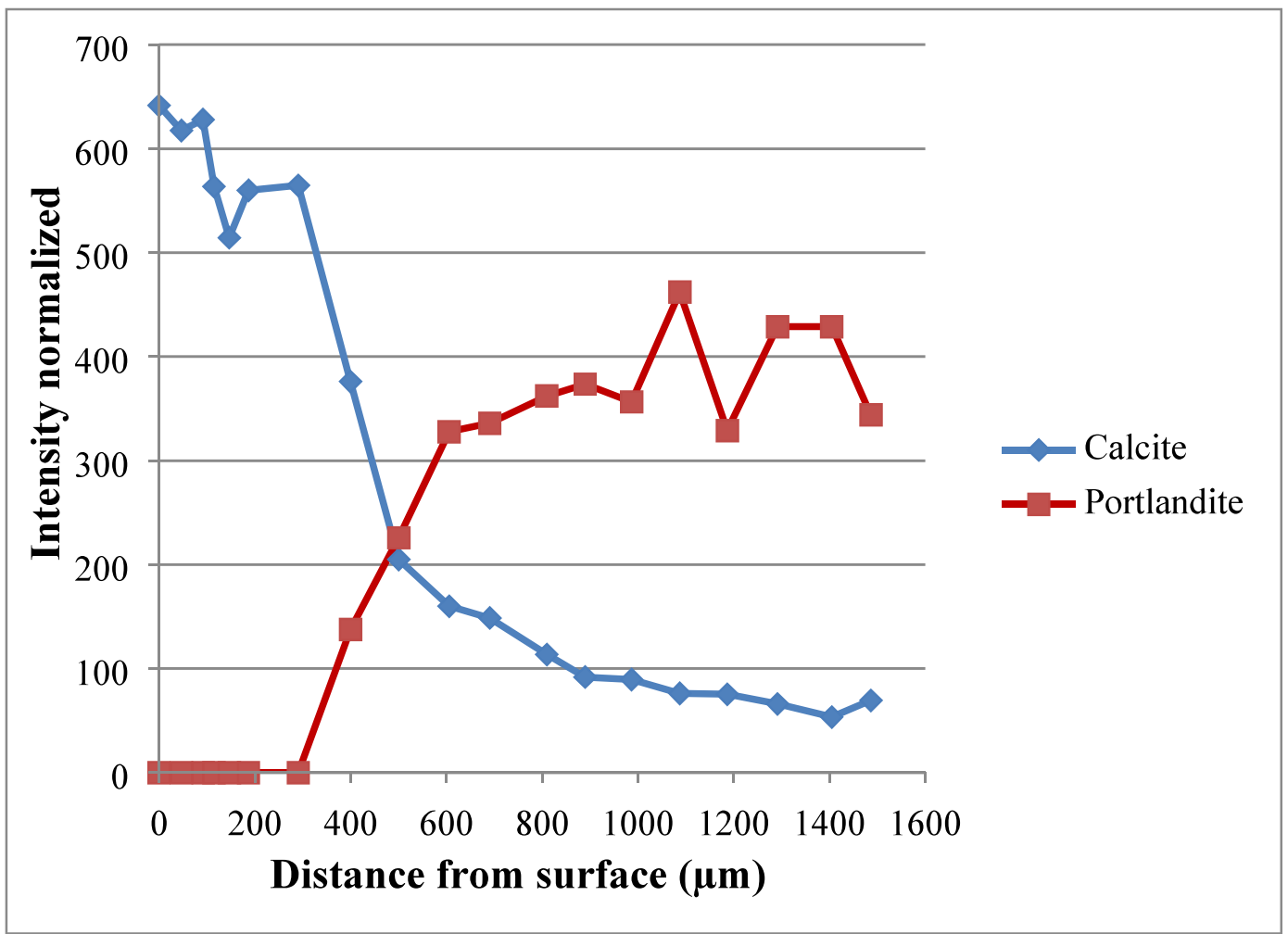

Figure 11: XRD profile of the untreated reference leached sample 


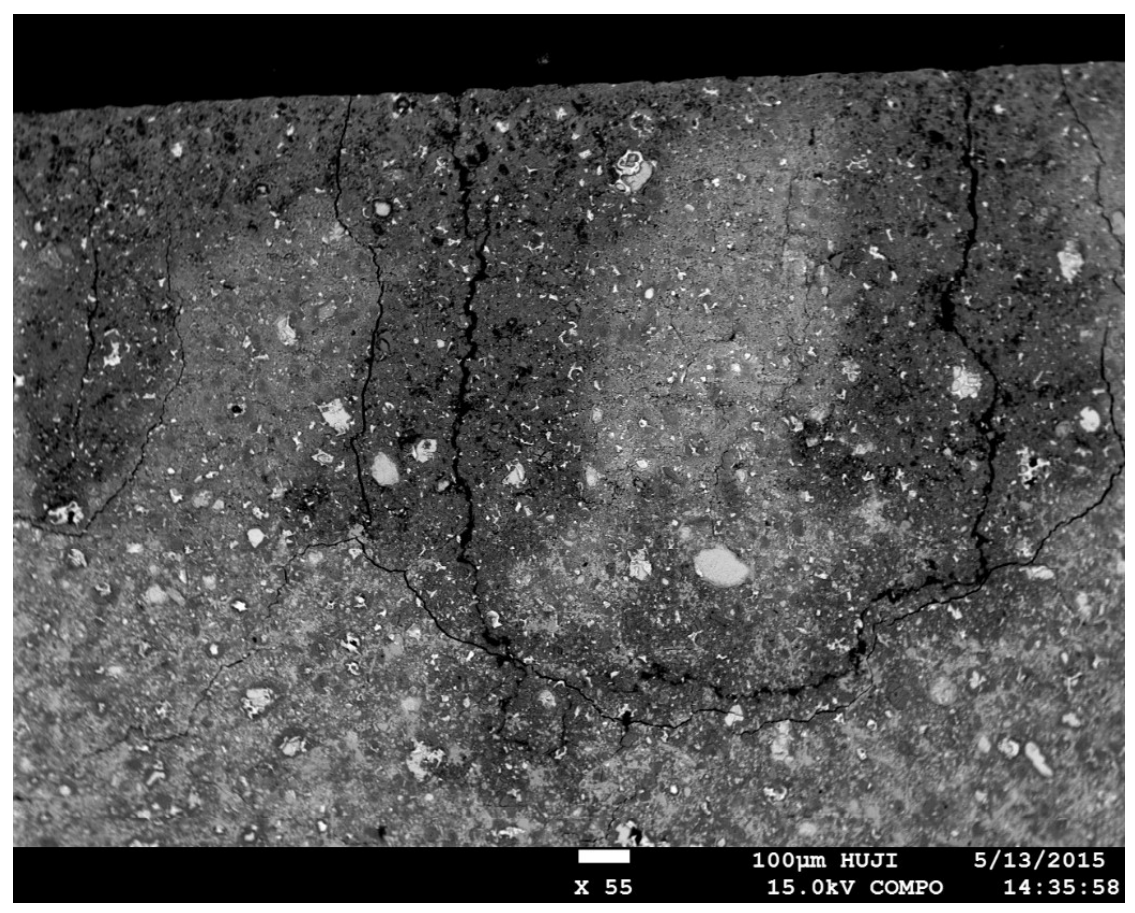

Figure 12: EPMA BSC image of leached sample after treatment in the climatic chamber under inert atmosphere. 

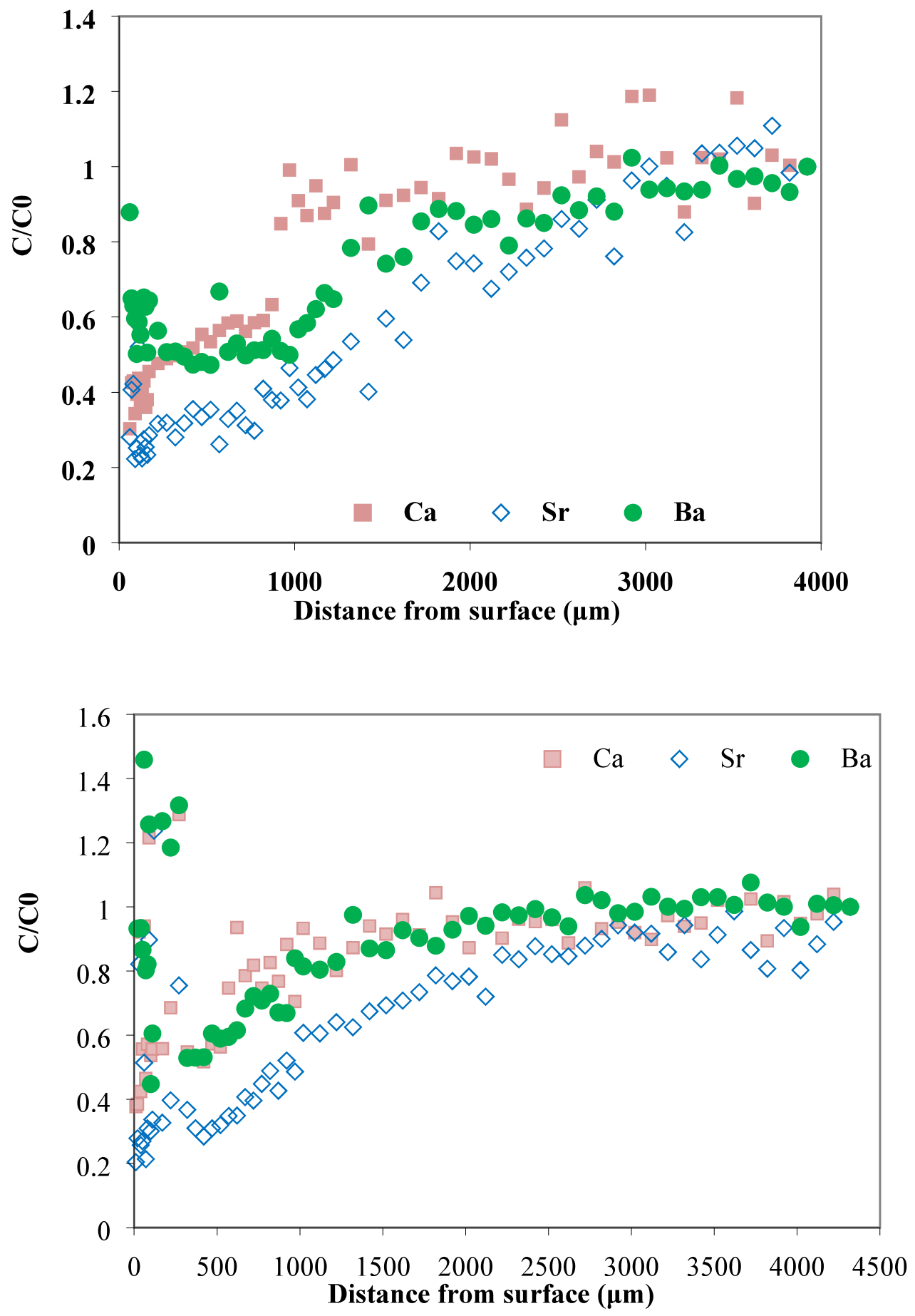

Figure 13: LA-ICP-MS Ca, $\mathrm{Ba}$ and $\mathrm{Sr}$ concentration variation along a cross section in the two leached samples after treatment under inert atmosphere:(a) climatic chamber (b) irradiated 

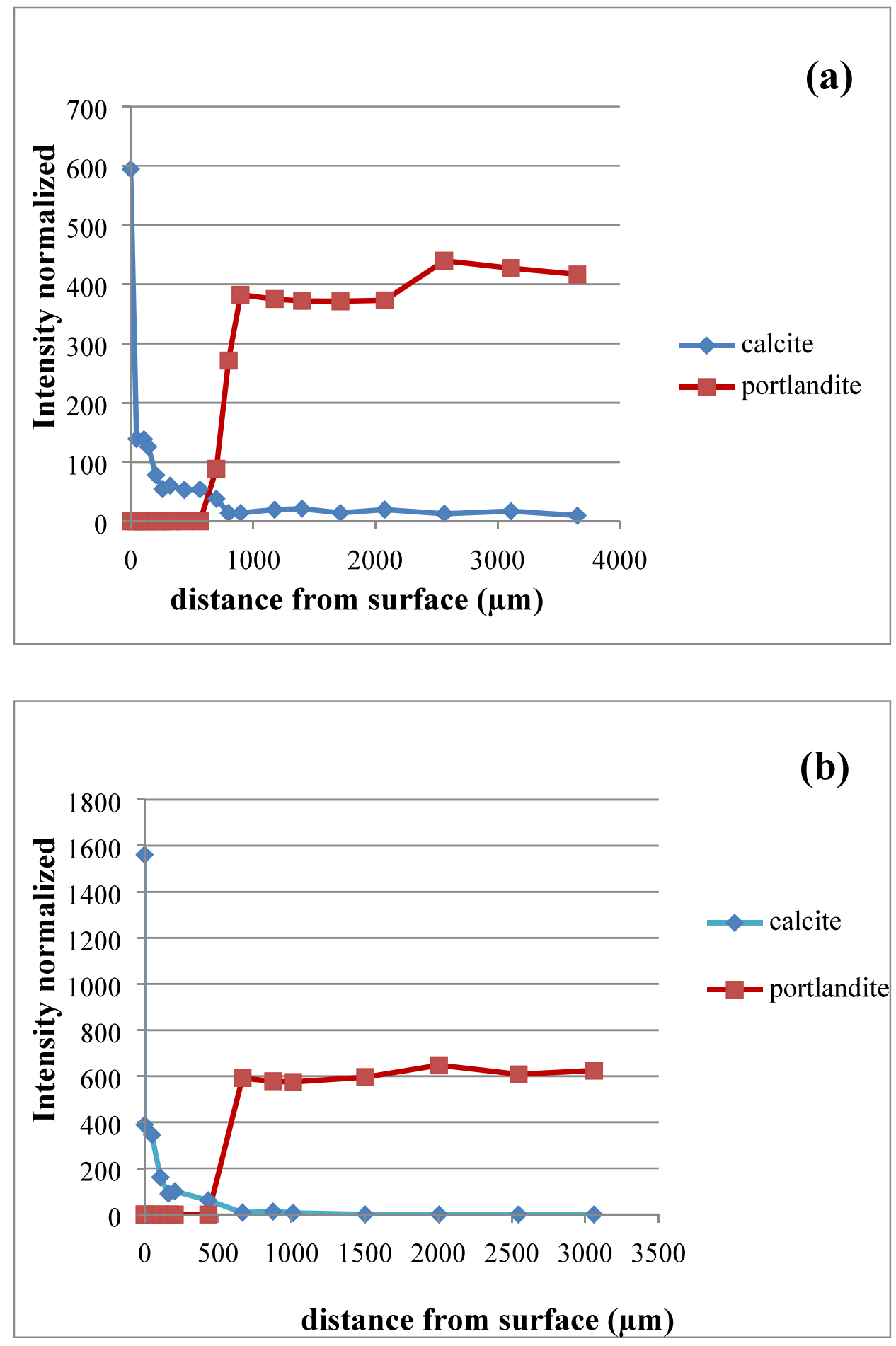

Figure 14: Phase distribution along a cross section in the leached samples after treatment under inert atmosphere (a) in the climatic chamber (b) irradiated 


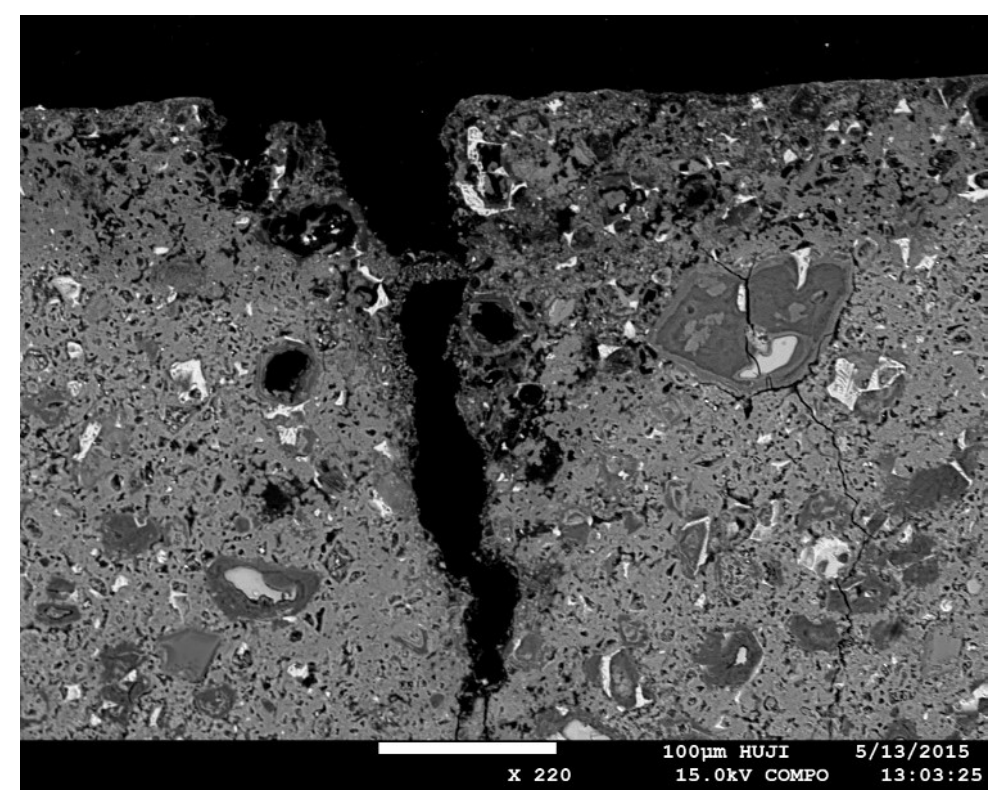

Figure 15: EPMA BSE images of leached sample treated in the climatic chamber under atmospheric conditions. Zoom into the near edge area (surface on the top). 

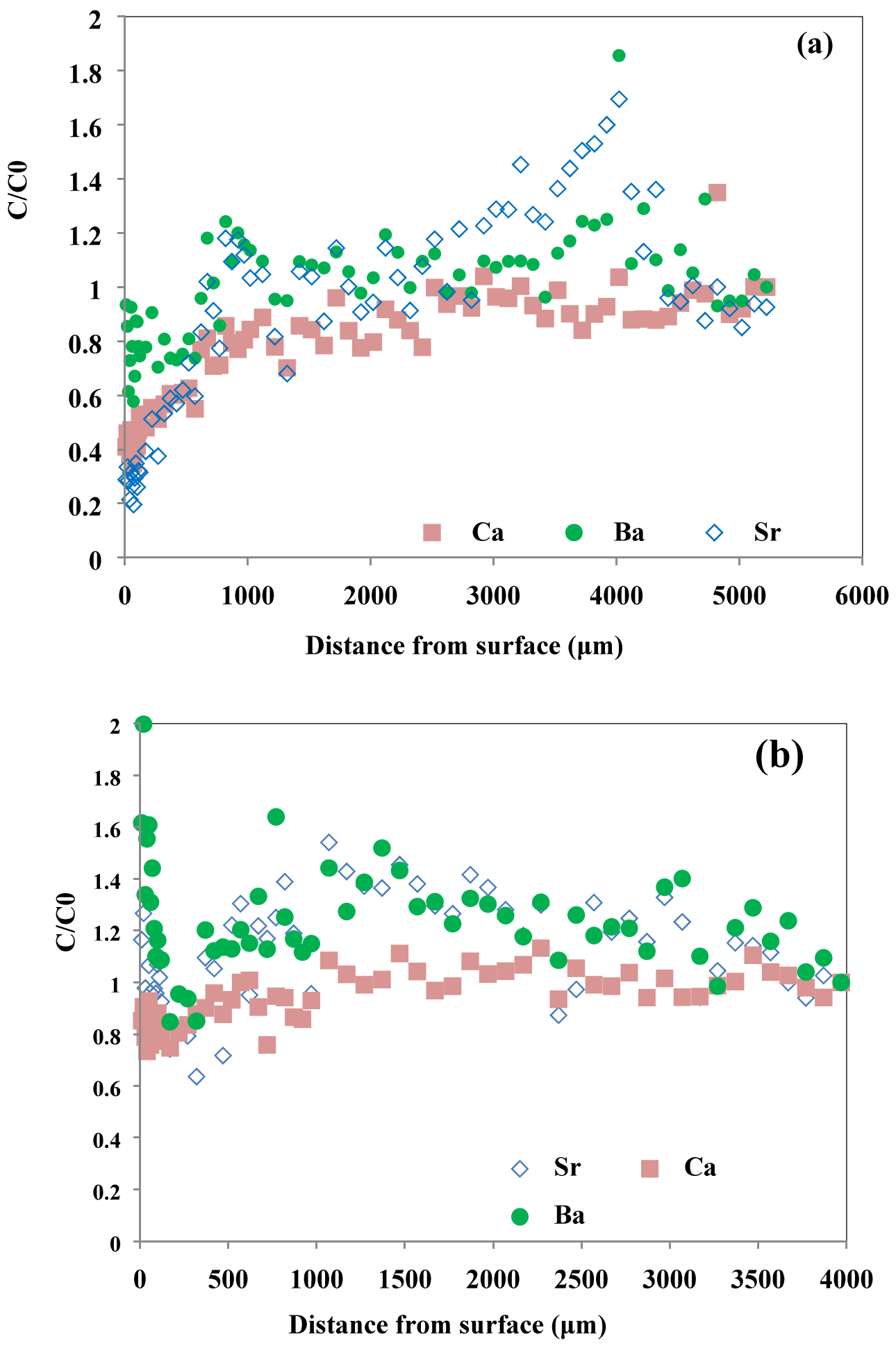

Figure 16: The $\mathrm{Ca}, \mathrm{Ba}$ and $\mathrm{Sr}$ concentrations along a cross section in leached samples after treatment under atmospheric conditions; (a) in the climatic chamber (b) irradiated 

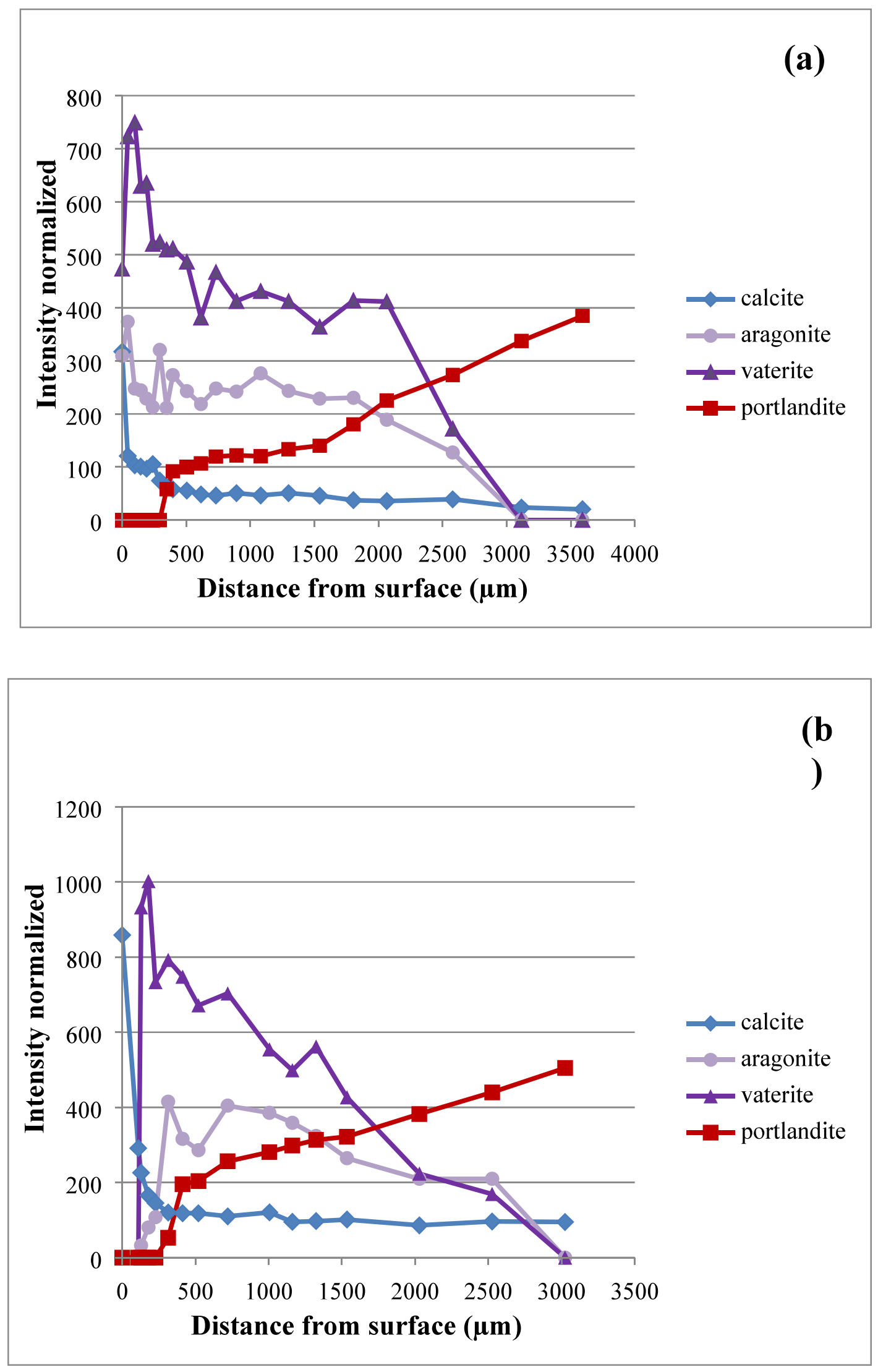
Figure 17: Phase distribution along a cross section in the leached samples after treatment under atmospheric conditions (a) in the climatic chamber (b) irradiated 